\title{
Variability and quasi-decadal changes in the methane budget over the period 2000-2012
}

Marielle Saunois ${ }^{1}$, Philippe Bousquet ${ }^{1}$, Ben Poulter ${ }^{2}$, Anna Peregon ${ }^{1}$, Philippe Ciais ${ }^{1}$, Josep G. Canadell ${ }^{3}$, Edward J. Dlugokencky ${ }^{4}$, Giuseppe Etiope ${ }^{5,6}$, David Bastviken ${ }^{7}$, Sander Houweling ${ }^{8,9}$, Greet Janssens-Maenhout ${ }^{10}$, Francesco N. Tubiello ${ }^{11}$, Simona Castaldi ${ }^{12,13,14}$, Robert B. Jackson ${ }^{15}$, Mihai Alexe ${ }^{10}$, Vivek K. Arora ${ }^{16}$, David J. Beerling ${ }^{17}$, Peter Bergamaschi ${ }^{10}$, Donald R. Blake ${ }^{18}$, Gordon Brailsford ${ }^{19}$, Lori Bruhwiler ${ }^{4}$, Cyril Crevoisier $^{20}$, Patrick Crill ${ }^{21}$, Kristofer Covey ${ }^{22}$, Christian Frankenberg ${ }^{23,24}$, Nicola Gedney ${ }^{25}$, Lena Höglund-Isaksson ${ }^{26}$, Misa Ishizawa ${ }^{27}$, Akihiko Ito ${ }^{27}$, Fortunat Joos ${ }^{28}$, Heon-Sook Kim ${ }^{27}$, Thomas Kleinen ${ }^{29}$, Paul Krummel $^{30}$, Jean-François Lamarque ${ }^{31}$, Ray Langenfelds ${ }^{30}$, Robin Locatelli ${ }^{1}$, Toshinobu Machida ${ }^{27}$, Shamil Maksyutov ${ }^{27}$, Joe R. Melton ${ }^{32}$, Isamu Morino ${ }^{27}$, Vaishali Naik ${ }^{33}$, Simon O'Doherty ${ }^{34}$, Frans-Jan W. Parmentier ${ }^{35}$, Prabir K. Patra ${ }^{36}$, Changhui Peng ${ }^{37,38}$, Shushi Peng ${ }^{1,39}$, Glen P. Peters ${ }^{40}$, Isabelle Pison ${ }^{1}$, Ronald Prinn $^{41}$, Michel Ramonet ${ }^{1}$, William J. Riley ${ }^{42}$, Makoto Saito ${ }^{27}$, Monia Santini ${ }^{13,14}$, Ronny Schroeder ${ }^{43}$, Isobel J. Simpson ${ }^{18}$, Renato Spahni ${ }^{28}$, Atsushi Takizawa ${ }^{44}$, Brett F. Thornton ${ }^{21}$, Hanqin Tian ${ }^{45}$, Yasunori Tohjima ${ }^{27}$, Nicolas Viovy ${ }^{1}$, Apostolos Voulgarakis ${ }^{46}$, Ray Weiss ${ }^{47}$, David J. Wilton ${ }^{17}$, Andy Wiltshire ${ }^{48}$, Doug Worthy ${ }^{49}$, Debra Wunch $^{50}$, Xiyan Xu ${ }^{42,51}$, Yukio Yoshida ${ }^{27}$, Bowen Zhang ${ }^{45}$, Zhen Zhang ${ }^{2,52}$, and Qiuan Zhu ${ }^{38}$

${ }^{1}$ Laboratoire des Sciences du Climat et de l'Environnement, LSCE-IPSL (CEA-CNRS-UVSQ), Université Paris-Saclay, 91191 Gif-sur-Yvette, France

${ }^{2}$ NASA Goddard Space Flight Center, Biospheric Sciences Laboratory, Greenbelt, MD 20771, USA

${ }^{3}$ Global Carbon Project, CSIRO Oceans and Atmosphere, Canberra, ACT 2601, Australia

${ }^{4}$ NOAA ESRL, 325 Broadway, Boulder, CO 80305, USA

${ }^{5}$ Istituto Nazionale di Geofisica e Vulcanologia, Sezione Roma 2, via V. Murata 605, Roma 00143 , Italy

${ }^{6}$ Faculty of Environmental Science and Engineering, Babes Bolyai University, Cluj-Napoca, Romania

${ }^{7}$ Department of Thematic Studies - Environmental Change, Linköping University, 58183 Linköping, Sweden

${ }^{8}$ Netherlands Institute for Space Research (SRON), Sorbonnelaan 2, 3584 CA, Utrecht, the Netherlands

${ }^{9}$ Institute for Marine and Atmospheric Research Sorbonnelaan 2, 3584 CA, Utrecht, the Netherlands

${ }^{10}$ European Commission Joint Research Centre, Ispra (Va), Italy

${ }^{11}$ Statistics Division, Food and Agriculture Organization of the United Nations (FAO),

Viale delle Terme di Caracalla, Rome 00153, Italy

${ }^{12}$ Dipartimento di Scienze e Tecnologie Ambientali Biologiche e Farmaceutiche, Seconda Università di Napoli, via Vivaldi 43, 81100 Caserta, Italy

${ }^{13}$ Far East Federal University (FEFU), Vladivostok, Russky Island, Russia

${ }^{14}$ Euro-Mediterranean Center on Climate Change, Via Augusto Imperatore 16, 73100 Lecce, Italy

${ }^{15}$ School of Earth, Energy and Environmental Sciences, Stanford University, Stanford, CA 94305-2210, USA

${ }^{16}$ Canadian Centre for Climate Modelling and Analysis, Climate Research Division, Environment and Climate Change Canada, Victoria, BC, V8W 2Y2, Canada

${ }^{17}$ Department of Animal and Plant Sciences, University of Sheffield, Sheffield S10 2TN, UK

${ }^{18}$ University of California Irvine, 570 Rowland Hall, Irvine, CA 92697, USA

${ }^{19}$ National Institute of Water and Atmospheric Research, 301 Evans Bay Parade, Wellington, New Zealand

${ }^{20}$ Laboratoire de Météorologie Dynamique, LMD/IPSL, CNRS École polytechnique,

Université Paris-Saclay, 91120 Palaiseau, France

${ }^{21}$ Department of Geological Sciences and Bolin Centre for Climate Research, Svante Arrhenius väg 8,

10691 Stockholm, Sweden

${ }^{22}$ School of Forestry and Environmental Studies, Yale University, New Haven, CT 06511, USA

${ }^{23}$ California Institute of Technology, Geological and Planetary Sciences, Pasadena, CA, USA 
${ }^{24}$ Jet Propulsion Laboratory, M/S 183-601, 4800 Oak Grove Drive, Pasadena, CA 91109, USA

${ }^{25}$ Met Office Hadley Centre, Joint Centre for Hydrometeorological Research, Maclean Building, Wallingford OX10 8BB, UK

${ }^{26}$ Air Quality and Greenhouse Gases program (AIR), International Institute for Applied Systems Analysis (IIASA), 2361

Laxenburg, Austria

${ }^{27}$ Center for Global Environmental Research, National Institute for Environmental Studies (NIES), Onogawa 16-2, Tsukuba, Ibaraki 305-8506, Japan

${ }^{28}$ Climate and Environmental Physics, Physics Institute and Oeschger Center for Climate Change Research, University of Bern, Sidlerstr. 5, 3012 Bern, Switzerland

${ }^{29}$ Max Planck Institute for Meteorology, Bundesstrasse 53, 20146 Hamburg, Germany

${ }^{30}$ CSIRO Oceans and Atmosphere, Aspendale, Victoria 3195, Australia

${ }^{31}$ NCAR, P.O. Box 3000, Boulder, CO 80307-3000, USA

${ }^{32}$ Climate Research Division, Environment and Climate Change Canada, Victoria, BC, V8W 2Y2, Canada

${ }^{33}$ NOAA, GFDL, 201 Forrestal Rd., Princeton, NJ 08540, USA

${ }^{34}$ School of Chemistry, University of Bristol, Cantock's Close, Clifton, Bristol BS8 1TS, UK

${ }^{35}$ Department of Arctic and Marine Biology, Faculty of Biosciences, Fisheries and Economics, UiT: The Arctic

University of Norway, 9037 Troms $\emptyset$, Norway

${ }^{36}$ Department of Environmental Geochemical Cycle Research and Institute of Arctic Climate and Environment Research,

JAMSTEC, 3173-25 Showa-machi, Kanazawa-ku, Yokohama, 236-0001, Japan

${ }^{37}$ Department of Biological Sciences, Institute of Environmental Sciences, University of Quebec at Montreal,

Montreal, QC H3C 3P8, Canada

${ }^{38}$ State Key Laboratory of Soil Erosion and Dryland Farming on the Loess Plateau, Northwest A\&F University, Yangling, Shaanxi 712100, China

${ }^{39}$ Sino-French Institute for Earth System Science, College of Urban and Environmental Sciences, Peking University, Beijing 100871, China

${ }^{40}$ CICERO Center for International Climate Research, Pb. 1129 Blindern, 0318 Oslo, Norway

${ }^{41}$ Massachusetts Institute of Technology (MIT), Building 54-1312, Cambridge, MA 02139, USA

${ }^{42}$ Climate and Ecosystem Sciences Division, Lawrence Berkeley National Lab, 1 Cyclotron Road, Berkeley, CA 94720, USA

${ }^{43}$ Department of Civil and Environmental Engineering, University of New Hampshire, Durham, NH 03824, USA

${ }^{44}$ Japan Meteorological Agency (JMA), 1-3-4 Otemachi, Chiyoda-ku, Tokyo 100-8122, Japan

${ }^{45}$ International Center for Climate and Global Change Research, School of Forestry and Wildlife Sciences, Auburn University, 602 Duncan Drive, Auburn, AL 36849, USA

${ }^{46}$ Space and Atmospheric Physics, Blackett Laboratory, Imperial College London, London SW7 2AZ, UK

${ }^{47}$ Scripps Institution of Oceanography (SIO), University of California San Diego, La Jolla, CA 92093, USA

${ }^{48}$ Met Office Hadley Centre, FitzRoy Road, Exeter, EX1 3PB, UK

${ }^{49}$ Environment Canada, 4905 , rue Dufferin, Toronto, Canada

${ }^{50}$ Department of Physics, University of Toronto, 60 St. George Street, Toronto, Ontario, Canada

${ }^{51}$ CAS Key Laboratory of Regional Climate-Environment for Temperate East Asia, Institute of Atmospheric Physics, Chinese Academy of Sciences, Beijing 100029, China

${ }^{52}$ Swiss Federal Research Institute WSL, Birmensdorf 8059, Switzerland

Correspondence to: Marielle Saunois (marielle.saunois@1sce.ipsl.fr)

Received: 30 March 2017 - Discussion started: 18 April 2017

Revised: 18 July 2017 - Accepted: 20 July 2017 - Published: 20 September 2017

\begin{abstract}
Following the recent Global Carbon Project (GCP) synthesis of the decadal methane $\left(\mathrm{CH}_{4}\right)$ budget over 2000 2012 (Saunois et al., 2016), we analyse here the same dataset with a focus on quasi-decadal and inter-annual variability in $\mathrm{CH}_{4}$ emissions. The GCP dataset integrates results from topdown studies (exploiting atmospheric observations within an atmospheric inverse-modelling framework) and bottom-up models (including process-based models for estimating land
\end{abstract}

surface emissions and atmospheric chemistry), inventories of anthropogenic emissions, and data-driven approaches.

The annual global methane emissions from top-down studies, which by construction match the observed methane growth rate within their uncertainties, all show an increase in total methane emissions over the period 2000-2012, but this increase is not linear over the 13 years. Despite differences between individual studies, the mean emission anomaly of 
the top-down ensemble shows no significant trend in total methane emissions over the period 2000-2006, during the plateau of atmospheric methane mole fractions, and also over the period 2008-2012, during the renewed atmospheric methane increase. However, the top-down ensemble mean produces an emission shift between 2006 and 2008, leading to 22 [16-32] Tg $\mathrm{CH}_{4} \mathrm{yr}^{-1}$ higher methane emissions over the period 2008-2012 compared to 2002-2006. This emission increase mostly originated from the tropics, with a smaller contribution from mid-latitudes and no significant change from boreal regions.

The regional contributions remain uncertain in top-down studies. Tropical South America and South and East Asia seem to contribute the most to the emission increase in the tropics. However, these two regions have only limited atmospheric measurements and remain therefore poorly constrained.

The sectorial partitioning of this emission increase between the periods 2002-2006 and 2008-2012 differs from one atmospheric inversion study to another. However, all topdown studies suggest smaller changes in fossil fuel emissions (from oil, gas, and coal industries) compared to the mean of the bottom-up inventories included in this study. This difference is partly driven by a smaller emission change in China from the top-down studies compared to the estimate in the Emission Database for Global Atmospheric Research (EDGARv4.2) inventory, which should be revised to smaller values in a near future. We apply isotopic signatures to the emission changes estimated for individual studies based on five emission sectors and find that for six individual top-down studies (out of eight) the average isotopic signature of the emission changes is not consistent with the observed change in atmospheric ${ }^{13} \mathrm{CH}_{4}$. However, the partitioning in emission change derived from the ensemble mean is consistent with this isotopic constraint. At the global scale, the top-down ensemble mean suggests that the dominant contribution to the resumed atmospheric $\mathrm{CH}_{4}$ growth after 2006 comes from microbial sources (more from agriculture and waste sectors than from natural wetlands), with an uncertain but smaller contribution from fossil $\mathrm{CH}_{4}$ emissions. In addition, a decrease in biomass burning emissions (in agreement with the biomass burning emission databases) makes the balance of sources consistent with atmospheric ${ }^{13} \mathrm{CH}_{4}$ observations.

In most of the top-down studies included here, $\mathrm{OH}$ concentrations are considered constant over the years (seasonal variations but without any inter-annual variability). As a result, the methane loss (in particular through $\mathrm{OH}$ oxidation) varies mainly through the change in methane concentrations and not its oxidants. For these reasons, changes in the methane loss could not be properly investigated in this study, although it may play a significant role in the recent atmospheric methane changes as briefly discussed at the end of the paper.

\section{Introduction}

Methane $\left(\mathrm{CH}_{4}\right)$, the second most important anthropogenic greenhouse gas in terms of radiative forcing, is highly relevant to mitigation policy due to its shorter lifetime and its stronger warming potential compared to carbon dioxide. Atmospheric $\mathrm{CH}_{4}$ mole fraction has experienced a renewed and sustained increase since 2007 after almost 10 years of stagnation (Dlugokencky et al., 2009; Rigby et al., 2008; Nisbet et al., 2014, 2016). Over 2006-2013, the atmospheric $\mathrm{CH}_{4}$ growth rate was about $5 \mathrm{ppb} \mathrm{yr}^{-1}$ before reaching $12.7 \mathrm{ppb} \mathrm{yr}^{-1}$ in 2014 and $9.5 \mathrm{ppb} \mathrm{yr}^{-1}$ in 2015 (NOAA monitoring network: http://www.esrl.noaa.gov/gmd/ ccgg/trends_ch4/).

The growth rate of atmospheric methane is a very accurate measurement of the imbalance between global sources and sinks. Methane is emitted by anthropogenic sources (livestock including enteric fermentation and manure management; rice cultivation; solid waste and wastewater; fossil fuel production, transmission, and distribution; biomass burning) and natural sources (wetlands and other inland freshwaters, geological sources, hydrates, termites, wild animals). Methane is mostly destroyed in the atmosphere by hydroxyl radical $(\mathrm{OH})$ oxidation $(90 \%$ of the atmospheric sink). Other sinks include destruction by atomic oxygen and chlorine, in the stratosphere and in the marine boundary layer, respectively, and upland soil sink destruction by microbial methane oxidation. The changes in these sources and sinks can be investigated by different methods: bottom-up process-based models of wetland emissions (Melton et al., 2013; Bohn et al., 2015; Poulter et al., 2017), rice paddy emissions (Zhang et al. 2016), termite emissions (Sanderson, 1996; Kirschke et al., 2013, Supplement) and soil uptake (Curry, 2007), data-driven approaches for other natural fluxes (e.g. Bastviken et al., 2011; Etiope, 2015), atmospheric chemistry climate model for methane oxidation by OH (John et al., 2012; Naik et al., 2013; Voulgarakis et al., 2013; Holmes et al., 2013), bottom-up inventories for anthropogenic emissions (e.g. Emission Database for Global Atmospheric Research, EDGAR; US Environmental Protection Agency, USEPA; Food and Agriculture Organization, FAO; Greenhouse Gas - Air Pollution Interactions and Synergies model, GAINS), observation-driven models for biomass burning emissions (e.g. Global Fire Emissions Database, GFED) and finally by atmospheric inversions, which optimally combine methane atmospheric observations within a chemistry transport model, and a prior knowledge of sources and sinks (inversions are also called top-down approaches, e.g. Bergamaschi et al., 2013; Houweling et al., 2014; Pison et al., 2013).

The renewed increase in atmospheric methane since 2007 has been investigated in the past recent years; atmospheric concentration-based studies suggest a mostly tropical signal, with a small contribution from the mid-latitudes and no clear change from high latitudes (Bousquet et al., 2011; Bergam- 
aschi et al., 2013; Bruhwiler et al., 2014; Dlugokencky et al., 2011; Patra et al., 2016; Nisbet et al., 2016). The year 2007 was found to be a year with exceptionally high emissions from the Arctic (e.g. Dlugokencky et al., 2009), but it does not mean that Arctic emissions were persistently higher during the entire period 2008-2012. Attribution of the renewed atmospheric $\mathrm{CH}_{4}$ growth to specific source and sink processes is still being debated. Bergamaschi et al. (2013) found that anthropogenic emissions were the most important contributor to the methane growth rate increase after 2007, though smaller than in the EDGARv4.2FT2010 inventory. In contrast, Bousquet et al. (2011) explained the methane increases in 2007-2008 by an increase mainly in natural emissions, while Poulter et al. (2017) did not find significant trends in global wetland emissions from an ensemble of wetland models over the period 2000-2012. This flat trend over the decade is associated with large year-toyear variations (e.g. 2010-2011 in the tropics) that limit its robustness together with sensitivities to the choice of the inventory chosen to represent the wetland extent. McNorton et al. (2016b) using a single wetland emission model with a different wetland dynamics scheme also concluded a small increase (3\%) in wetland emissions relative to 19932006. Associated with the atmospheric $\mathrm{CH}_{4}$ mixing ratio increase, the atmospheric $\delta^{13} \mathrm{C}_{-} \mathrm{CH}_{4}$ shows a continuous decrease since 2007 (e.g. Nisbet al., 2016), pointing towards increasing sources with depleted $\delta^{13} \mathrm{C}^{-} \mathrm{CH}_{4}$ (microbial) and/or decreasing sources with enriched $\delta^{13} \mathrm{C}_{-} \mathrm{CH}_{4}$ (pyrogenic, thermogenic). Using a box model combining $\delta^{13} \mathrm{C}_{-} \mathrm{CH}_{4}$ and $\mathrm{CH}_{4}$ observations, two recent studies infer a dominant role of increasing microbial emissions (more depleted in ${ }^{13} \mathrm{C}$ than thermogenic and pyrogenic sources) to explain the higher $\mathrm{CH}_{4}$ growth rate after ca. 2006. Schaefer et al. (2016) hypothesised (but did not prove) that the increasing microbial source was from agriculture rather than from natural wetlands; however, given the uncertainties in isotopic signatures, the evidence against wetlands is not strong. Schwietzke et al. (2016), using updated estimates of the source isotopic signatures (Sherwood et al., 2017) with rather narrow uncertainty ranges also find a positive trend in microbial emissions. In a scenario where biomass burning emissions are constant over time, they inferred decreasing fossil fuel emissions, in disagreement with emission inventories. However, the global burned area is suggested to have decreased $\left(-1.2 \% \mathrm{yr}^{-1}\right.$ ) over the period 2000-2012 (Giglio et al., 2013), leading to a decrease in biomass burning emissions (http://www.globalfiredata.org/figures.html). In a second scenario including a $1.2 \% \mathrm{yr}^{-1}$ decrease in biomass burning emissions, Schwietzke et al. (2016) find fossil fuel emissions close to constant over time, when coal production significantly increased, mainly from China.

Atmospheric observations of ethane, a species co-emitted with methane in the oil and gas upstream sector, can be used to estimate methane emissions from this sector (e.g. Aydin et al, 2011; Wennberg et al., 2012; Nicewonger et al., 2016). The historical record of atmospheric ethane suggests an increase in ethane sources until the 1980s and then a decrease driven by fossil-fuel-related emissions until the early 2000s (Aydin et al., 2011). Over the 2007-2014 period, Hausmann et al. (2016) suggested a significant increase in oil and gas methane emissions contributing to the increase in total methane emissions. However, this study, as many others, relies on emission ratios of ethane to methane, which are uncertain and may vary substantially over the years (e.g. Wunch et al., 2016), yet this potential variation over time is not well documented. The increase in methane mole fractions could also be due to a decrease in $\mathrm{OH}$ global concentrations (Rigby et al., 2008; Holmes et al., 2013). Although $\mathrm{OH}$ year-to-year variability appears to be smaller than previously thought (e.g. Montzka et al., 2011), a long-term trend can still strongly impact the atmospheric methane growth rate as a $1 \%$ change in $\mathrm{OH}$ corresponds to a $5 \mathrm{Tg}$ change in methane emissions (Dalsoren et al., 2009). Indeed, after an increase in $\mathrm{OH}$ concentrations over the period 1970-2007, Dalsoren et al. (2016) found constant OH concentrations since 2007, and Rigby et al. (2017) found a decrease in $\mathrm{OH}$ concentrations, with both results possibly contributing to the observed increase in methane growth rate and therefore limiting the required changes in methane emissions inferred by top-down studies. However, Turner et al. (2017) highlight the difficulty in disentangling the contribution in emission or sink changes when $\mathrm{OH}$ concentrations are weakly constrained by atmospheric measurements.

Using top-down approaches, an accurate attribution of changes in methane emissions per region is difficult due to the sparse coverage of surface networks (e.g. Dlugokencky et al., 2011). Satellite data offer a better coverage in some poorly sampled regions (tropics), and progress has been made in improving satellite retrievals of $\mathrm{CH}_{4}$ column mole fractions (e.g. Butz et al., 2011; Cressot et al., 2014). However, the complete exploitation of remote sensing of $\mathrm{CH}_{4}$ column gradients in the atmosphere to infer regional sources is still limited by relatively poor accuracy and gaps in the data, although progress has been made by moving from SCIAMACHY (SCanning Imaging Absorption SpectroMeter for Atmospheric CHartographY) to GOSAT (Greenhouse Gases Observing Satellite; Buchwitz et al., 2015; Cressot et al., 2016). Also, the chemistry transport models often fail to correctly reproduce the methane vertical gradient, especially in the stratosphere (Saad et al., 2016; Wang et al., 2016), and this misrepresentation in the models may impact the inferred surface fluxes when constrained by total column observations. Furthermore, uncertainties in top-down estimates stem from uncertainties in atmospheric transport and the setup and data used in the inverse systems (Locatelli et al., 2015; Patra et al., 2011).

One approach to address inversion uncertainties is to gather an ensemble of transport models and inversions. Instead of interpreting one single model to discuss the methane budget changes, here we take advantage of an ensemble of 
published studies to extract robust changes and patterns observed since 2000 and in particular since the renewed increase after 2007. This approach allows accounting for the model-to-model uncertainties in detecting robust changes of emissions (Cressot et al., 2016). Attributing sources to sectors (e.g. agriculture vs. fossil) or types (e.g. microbial vs. thermogenic) using inverse systems is challenging if no additional constraints, such as isotopes, are used to separate the different methane sources, which often overlap geographically. Assimilating only $\mathrm{CH}_{4}$ observations, the separation of different sources relies only on their different seasonality (e.g. rice cultivation, biomass burning, wetlands), on the signal of synoptic peaks related to regional emissions when continuous observations are available, or on distinct spatial distributions. Using isotopic information such as $\delta^{13} \mathrm{C}_{-} \mathrm{CH}_{4}$ brings some additional constraints on source partitioning to separate microbial vs. fossil and fire emissions, or to separate regions with a dominant source (e.g. agriculture in India versus wetlands in Amazonia), but $\delta^{13} \mathrm{C}_{-} \mathrm{CH}_{4}$ alone cannot further separate microbial emissions between agriculture, wetlands, termites, or freshwaters with enough confidence due to uncertainties in their close isotopic signatures.

The Global Carbon Project (GCP) has provided a collaborative platform for scientists from different disciplinary fields to share their individual expertise and synthesise the current understanding of the global methane budget. Following the first GCP global methane budget published by Kirschke et al. (2013) and using the same dataset as the budget update by Saunois et al. (2016) for 2000-2012, we analyse here the results of an ensemble of top-down and bottom-up approaches in order to determine the robust features that could explain the variability and quasi-decadal changes in $\mathrm{CH}_{4}$ growth rate since 2000. In particular, this paper aims to highlight the most likely emission changes that could contribute to the observed positive trend in methane mole fractions since 2007. However, we do not address the contribution of the methane sinks during this period. Indeed, for most of the models, the soil sink is from climatological estimates and the oxidant concentration fields $(\mathrm{OH}, \mathrm{Cl}, \mathrm{O} 1 \mathrm{D})$ are assumed constant over the years. The global mean of $\mathrm{OH}$ concentrations was generally optimised against methyl-chloroform observations (e.g. Montzka et al., 2011), but no inter-annual variability is applied. It should be kept in mind that any $\mathrm{OH}$ change in the atmosphere will limit (in case of decreasing $\mathrm{OH}$ ) or enhance (in case of increasing $\mathrm{OH}$ ) the methane emission changes that are required to explain the observed atmospheric methane recent increase (e.g. Dalsoren et al., 2016; Rigby et al., 2017), as further discussed in Sect. 4.

Section 2 presents the ensemble of bottom-up and topdown approaches used in this study as well as the common data processing operated. The main results based on this ensemble are presented and discussed in Sect. 3 through global and regional assessments of the methane emission changes as well as process contributions. We discuss these results in
Sect. 4 in the context of the recent literature summarised in the introduction and draw some conclusions in Sect. 5.

\section{Methods}

The datasets used in this paper were those collected and published in The Global Methane Budget 2000-2012 (Saunois et al., 2016). The decadal budget is publicly available at http://doi.org/10.3334/CDIAC/Global_Methane_Budget_ 2016_V1.1 and on the Global Carbon Project website. Here, we only describe the main characteristics of the datasets and the reader may refer to the aforementioned detailed paper. The datasets include an ensemble of global top-down approaches as well as bottom-up estimates of the sources and sinks of methane.

\subsection{Top-down studies}

The top-down estimates of methane sources and sinks are provided by eight global inverse systems, which optimally combine a prior knowledge of fluxes with atmospheric observations, both with their associated uncertainties, into a chemistry transport model in order to infer methane sources and sinks at specific spatial and temporal scales. Eight inverse systems have provided a total of 30 inversions over 2000-2012 or shorter periods (Table 1). The longest time series of optimised methane fluxes are provided by inversions using surface in situ measurements (15). Some surfacebased inversions were provided over time periods shorter than 10 years (7). Satellite-based inversions (8) provide estimates over shorter time periods (2003-2012 with SCIAMACHY; from June 2009 to 2012 using TANSO/GOSAT). As a result, the discussion presented in this paper will be essentially based on surface-based inversions as GOSAT offers too short a time series and SCIAMACHY is associated with large systematic errors that need ad hoc corrections (e.g. Bergamaschi et al., 2013). Most of the inverse systems estimate the total net methane emission fluxes at the surface (i.e. surface sources minus soil sinks), although some systems solve for a few individual source categories (Table 1). In order to speak in terms of emissions, each inversion provided its associated soil sink fluxes that have been added to the associated net methane fluxes to obtain estimates of surface sources. Saunois et al. (2016) attempted to separate top-down emissions into five categories: wetland emissions, other natural emissions, emissions from agriculture and waste handling, biomass burning emissions (including agricultural fires), and fossil-fuel-related emissions. To obtain these individual estimates from those inversions only solving for the net flux, the prior contribution of each source category was used to split the posterior total sources into individual contributions. 
Table 1. List of the top-down estimates included in this paper.

\begin{tabular}{|c|c|c|c|c|c|c|}
\hline Model & Institution & Observation used & $\begin{array}{l}\text { Time } \\
\text { period }\end{array}$ & Flux solved & $\begin{array}{r}\text { Number of } \\
\text { inversions }\end{array}$ & References \\
\hline Carbon Tracker- $\mathrm{CH}_{4}$ & NOAA & Surface stations & 2000-2009 & $\begin{array}{l}10 \text { terrestrial sources } \\
\text { and oceanic source }\end{array}$ & 1 & Bruhwiler et al. (2014) \\
\hline LMDZ-MIOP & LSCE-CEA & Surface stations & 1990-2013 & $\begin{array}{l}\text { Wetlands, biomass burning, and } \\
\text { other natural, } \\
\text { anthropogenic sources }\end{array}$ & 10 & Pison et al. (2013) \\
\hline LMDZ-PYVAR & LSCE-CEA & Surface stations & 2006-2012 & Net source & 6 & Locatelli et al. (2015) \\
\hline TM5 & SRON & Surface stations & $2003-2010$ & Net source & 1 & Houweling et al. (2014) \\
\hline TM5 & SRON & GOSAT satellite & $2009-2012$ & & 2 & \\
\hline TM5 & SRON & SCIAMACHY satellite & $2003-2010$ & & 1 & \\
\hline TM5 & EC-JRC & Surface stations & 2000-2012 & $\begin{array}{l}\text { Wetlands, rice, biomass burn- } \\
\text { ing, and all remaining sources }\end{array}$ & 1 & $\begin{array}{l}\text { Bergamaschi et al. (2013); } \\
\text { Alexe et al. (2015) }\end{array}$ \\
\hline TM5 & EC-JRC & GOSAT satellite & 2010-2012 & & 1 & \\
\hline GELCA & NIES & Surface stations & $2000-2012$ & $\begin{array}{l}\text { Natural (wetland, rice, termite), } \\
\text { anthropogenic (excluding rice), } \\
\text { biomass burning, soil sink }\end{array}$ & 1 & $\begin{array}{l}\text { Ishizawa et al. (2016); } \\
\text { Zhuravlev et al. (2013) }\end{array}$ \\
\hline ACTM & JAMSTEC & Surface stations & 2002-2012 & Net source & 1 & Patra et al. (2016) \\
\hline NIES-TM & NIES & Surface stations & 2010-2012 & $\begin{array}{l}\text { Biomass burning, } \\
\text { anthropogenic emissions } \\
\text { (excluding rice paddies), and all } \\
\text { natural sources (including rice } \\
\text { paddies) }\end{array}$ & 1 & $\begin{array}{l}\text { Kim et al. (2011); } \\
\text { Saito et al. (2016) }\end{array}$ \\
\hline NIES-TM & NIES & GOSAT satellite & 2010-2012 & & 1 & \\
\hline
\end{tabular}

\subsection{Bottom-up studies}

The bottom-up approaches gather inventories for anthropogenic emissions (agriculture and waste handling, fossilfuel-related emissions, biomass burning emissions), land surface models (wetland emissions), and diverse data-driven approaches (e.g, local measurement upscaling) for emissions from fresh waters and geological sources (Table 2). Anthropogenic emissions are from the Emission Database for Global Atmospheric Research (EDGARv4.1, 2010; EDGARV4.2FT2010, 2013), the United States Environmental Protection Agency, USEPA (USEPA, 2006, 2012), and the Greenhouse Gas - Air Pollution Interactions and Synergies (GAINS) model developed by the International Institute for Applied Systems Analysis (IIASA; Höglund-Isaksson, 2012). They report methane emissions from the following major sources: livestock (enteric fermentation and manure management); rice cultivation; solid waste and wastewater; fossil fuel production, transmission, and distribution. However, they differ in the level of detail by sector, by country, and by the emission factors used for some specific sectors and countries (Höglund-Isaksson et al., 2015). The Food and Agriculture Organization (FAO) FAOSTAT emissions dataset (FAOSTAT, 2017a, b) contains estimates of agricultural and biomass burning emissions (Tubiello et al., 2013, 2015). Biomass burning emissions are also taken from the Global Fire Emissions Database (version GFED3, van der Werf et al., 2010, and version GFED4s, Giglio et al., 2013; Randerson et al., 2012), the Fire Inventory from NCAR (FINN; Wiedinmyer et al., 2011), and the Global Fire Assimilation System (GFAS, Kaiser et al., 2012). For wetlands, we use the results of 11 land surface models driven by the same dynamic flooded area extent dataset from remote sensing (Schroeder et al., 2015) over the 2000-2012 period. These models differ mainly in their parameterisations of $\mathrm{CH}_{4}$ flux per unit area in response to climate and biotic factors (Poulter et al., 2017; Saunois et al., 2016).

\subsection{Data analysis}

The top-down and bottom-up estimates are gathered separately and compared as two ensembles for anthropogenic, biomass burning, and wetland emissions. For the bottom-up approaches, the category called "other natural" encompasses emissions from termites, wild animals, lakes, oceans, and natural geological seepage (Saunois et al., 2016). However, for most of these sources, limited information is available regarding their spatiotemporal distributions. Most of the inversions used here include termite and ocean emissions in their prior fluxes; some also include geological emissions (Table S1 in the Supplement). However, the emission distributions used by the inversions as prior fluxes are climatological and do not include any inter-annual variability. Geological methane emissions have played a role in past climate changes (Etiope et al., 2008). There is no study on decadal changes in geological $\mathrm{CH}_{4}$ emissions on continental and global scales, although it is known that they may increase or decrease in relation to seismic activity and variations of groundwater hydrostatic pressure (i.e. aquifer depletion).

Ocean emissions have been revised downward recently (Saunois et al., 2016). Inter-decadal changes in lake fluxes cannot be made in reliable ways because of the data scarcity and lack of validated models (Saunois et al., 2016). As a result of a lack of quantified evidences, variations of lakes, 
Table 2. List of the bottom-up studies included in this paper.

\begin{tabular}{|c|c|c|c|c|}
\hline $\begin{array}{l}\text { Bottom-up models } \\
\text { and inventories }\end{array}$ & Contribution & $\begin{array}{l}\text { Time period } \\
\text { (resolution) }\end{array}$ & Gridded & References \\
\hline EDGAR4.2 FT2010 & $\begin{array}{l}\text { Fossil fuels, agriculture } \\
\text { and waste, biofuel }\end{array}$ & 2000-2010 (yearly) & $\mathrm{X}$ & $\begin{array}{l}\text { EDGARv4.2FT2010 (2013); } \\
\text { Olivier et al. (2012) }\end{array}$ \\
\hline EDGARv4.2FT2012 & Total anthropogenic & 2000-2012 (yearly) & & $\begin{array}{l}\text { EDGARv4.2FT2012 (2014); } \\
\text { Olivier and } \\
\text { Janssens-Maenhout (2014); } \\
\text { Rogelj et al. (2014) }\end{array}$ \\
\hline EDGARv4.2EXT & $\begin{array}{l}\text { Fossil fuels, agriculture } \\
\text { and waste, biofuel }\end{array}$ & 1990-2013 (yearly) & & $\begin{array}{l}\text { Based on EDGARv4.1 } \\
\text { (EDGARv4.1, 2010); } \\
\text { this study }\end{array}$ \\
\hline USEPA & $\begin{array}{l}\text { Fossil fuels, agriculture } \\
\text { and waste, biofuel, }\end{array}$ & $\begin{array}{l}\text { 1990-2030 } \\
\text { (10-year interval, } \\
\text { interpolated in } \\
\text { this study) }\end{array}$ & & USEPA $(2006,2011,2012)$ \\
\hline IIASA GAINS ECLIPSE & $\begin{array}{l}\text { Fossil fuels, agriculture } \\
\text { and waste, biofuel }\end{array}$ & $\begin{array}{l}\text { 1990-2050 } \\
\text { (5-year interval, } \\
\text { interpolated in } \\
\text { this study) }\end{array}$ & $\mathrm{X}$ & $\begin{array}{l}\text { Höglund-Isaksson (2012); } \\
\text { Klimont et al. (2017) }\end{array}$ \\
\hline FAOSTAT & $\begin{array}{l}\text { Agriculture, biomass } \\
\text { burning }\end{array}$ & $\begin{array}{l}\text { Agriculture: } \\
\text { 1961-2012 } \\
\text { Biomass burning: } \\
\text { 1990-2014 }\end{array}$ & & Tubiello et al. $(2013,2015)$ \\
\hline GFEDv3 & Biomass burning & 1997-2011 & $\mathrm{X}$ & van der Werf et al. (2010) \\
\hline GFEDv4s & Biomass burning & $1997-2014$ & $\mathrm{X}$ & Giglio et al. (2013) \\
\hline GFASv1.0 & Biomass burning & $2000-2013$ & $\mathrm{X}$ & Kaiser et al. (2012) \\
\hline FINNv1 & Biomass burning & 2003-2014 & $\mathrm{X}$ & Wiedinmyer et al. (2011) \\
\hline CLM 4.5 & Natural wetlands & 2000-2012 & $\mathrm{X}$ & $\begin{array}{l}\text { Riley et al. (2011); } \\
\text { Xu et al. (2016) }\end{array}$ \\
\hline CTEM & Natural wetlands & $2000-2012$ & $\mathrm{X}$ & Melton and Arora (2016) \\
\hline DLEM & Natural wetlands & 2000-2012 & $\mathrm{X}$ & Tian et al. $(2010,2015)$ \\
\hline JULES & Natural wetlands & 2000-2012 & $\mathrm{X}$ & Hayman et al. (2014) \\
\hline LPJ-MPI & Natural wetlands & 2000-2012 & $\mathrm{X}$ & Kleinen et al. (2012) \\
\hline LPJ-wsl & Natural wetlands & 2000-2012 & $\mathrm{X}$ & Hodson et al. (2011) \\
\hline LPX-Bern & Natural wetlands & 2000-2012 & $\mathrm{X}$ & Spahni et al. (2011) \\
\hline ORCHIDEE & Natural wetlands & 2000-2012 & $\mathrm{X}$ & Ringeval et al. (2011) \\
\hline SDGVM & Natural wetlands & 2000-2012 & $\mathrm{X}$ & $\begin{array}{l}\text { Woodward and Lomas (2004); } \\
\text { Cao et al. (1996) }\end{array}$ \\
\hline TRIPLEX-GHG & Natural wetlands & 2000-2012 & $\mathrm{X}$ & Zhu et al. $(2014,2015)$ \\
\hline VISIT & Natural wetlands & 2000-2012 & $X$ & Ito and Inatomi (2012) \\
\hline
\end{tabular}

oceans, and geological sources are ignored in our bottomup analysis. However, it should be noted that possible variations of these sources are accounted for in the top-down approaches in the "other natural" category.

Some results are presented as box plots showing the 25 , 50 , and $75 \%$ percentiles. The whiskers show minimum and maximum values excluding outliers, which are shown as stars. The mean values are plotted as "+" symbols on the box plot. The values reported in the text are the mean (XX), minimum (YY), and maximum (ZZ) values as XX [YYZZ]. Some estimates rely on few studies so that meaningful $1 \sigma$ values cannot be computed. To consider that methane changes are positive or negative for a time-period (e.g. Figs. 3 and 4 in Sect. 3), we consider that the change is robustly positive or negative when both the first and third quartiles are positive or negative, respectively. 


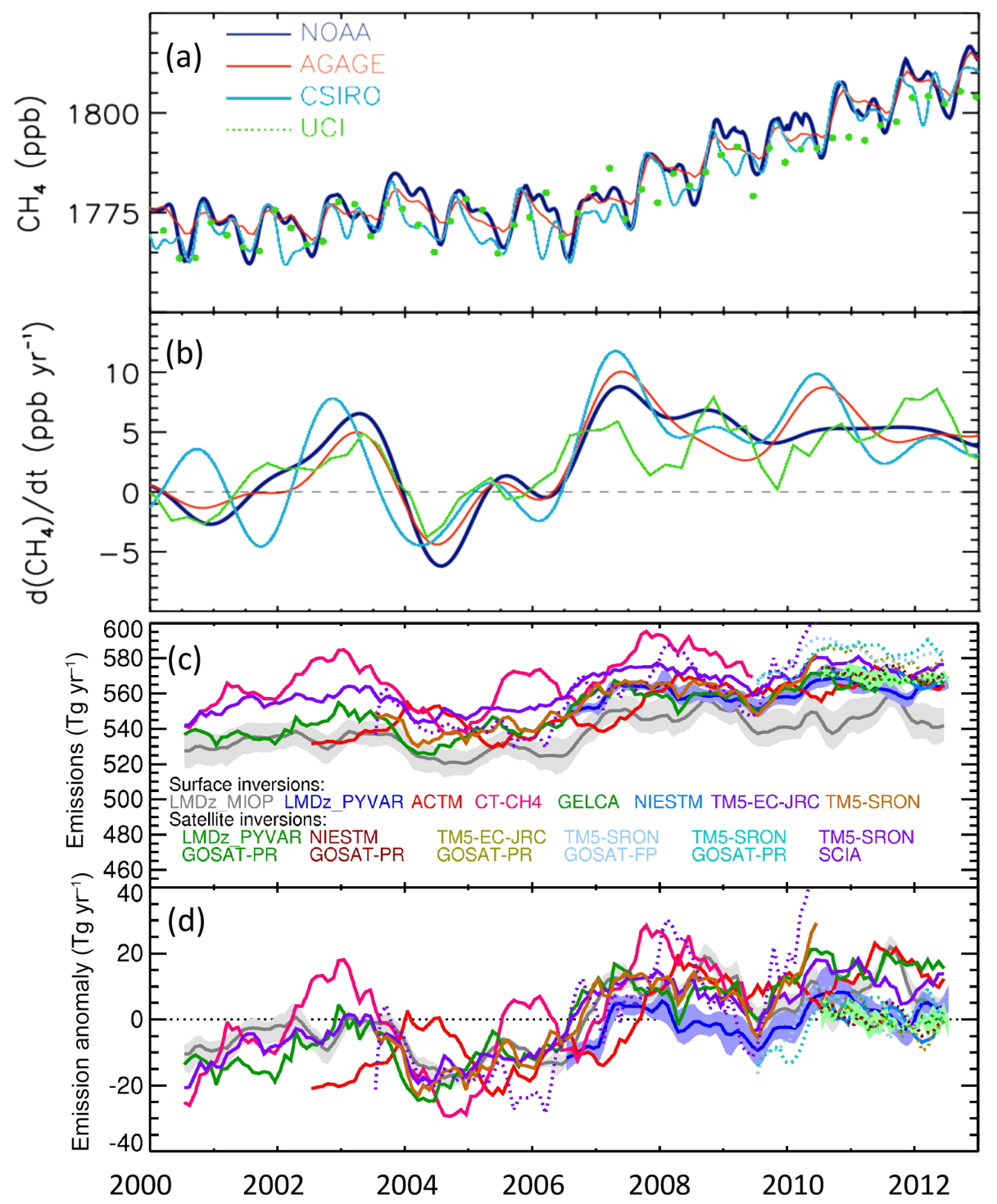

Figure 1. Evolution of the global methane cycle since 2000. (a) Observed atmospheric mixing ratios (ppb) as synthesised for four different surface networks with a global coverage (NOAA, AGAGE, CSIRO, UCI). (b) Global growth rate computed from (a) in ppb yr ${ }^{-1}$. The $12-$ month running mean of (c) the annual global emission $\left(\mathrm{Tg} \mathrm{CH}_{4} \mathrm{yr}^{-1}\right)$ and $(\mathbf{d})$ the annual global emission anomaly $\left(\mathrm{Tg}^{\prime} \mathrm{CH}_{4} \mathrm{yr}^{-1}\right)$ inferred by the ensemble of inversions.

\section{Results}

\subsection{Global methane variations in 2000-2012}

\subsubsection{Atmospheric changes}

The global average methane mole fractions are from four in situ atmospheric observation networks: the Earth System Research Laboratory from the US National Oceanic and Atmospheric Administration (NOAA ESRL; Dlugokencky et al., 1994), the Advanced Global Atmospheric Gases Experiment (AGAGE; Rigby et al., 2008), the Commonwealth Scientific and Industrial Research Organisation (CSIRO, Francey et al., 1999), and the University of California, Irvine (UCI;
Simpson et al., 2012). The four networks show a consistent evolution of the globally averaged methane mole fractions (Fig. 1a). The methane mole fractions refer here to the same NOAA2004A $\mathrm{CH}_{4}$ reference scale. The different sampling sites used to compute the global average and the sampling frequency may explain the observed differences between networks. Indeed, the UCI network samples atmospheric methane in the Pacific Ocean between $71^{\circ} \mathrm{N}$ and $47^{\circ} \mathrm{S}$ using flasks during specific campaign periods, while other networks use both continuous and flask measurements worldwide. During the first half of the 2000s, the methane mole fraction remained relatively stable $(1770-1785 \mathrm{ppb})$, with small positive growth rate until $2007\left(0.6 \pm 0.1 \mathrm{ppb} \mathrm{yr}^{-1}\right.$, 


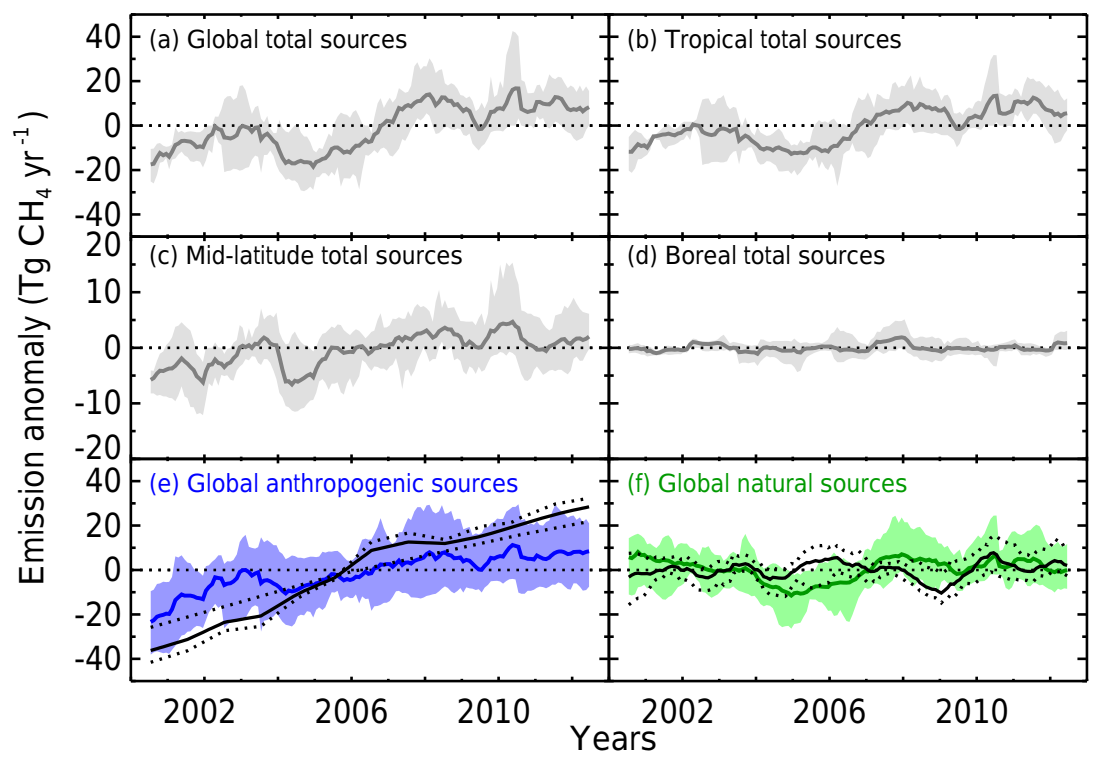

Figure 2. The 12-month running mean of annual methane emission anomalies (in $\mathrm{Tg}_{\mathrm{CH}} \mathrm{yr}^{-1}$ ) inferred by the ensemble of inversions (mean as the solid line and min-max range as the shaded area) in grey for (a) global, (b) tropical, (c) mid-latitudes, and (d) boreal total sources; in blue for (e) global anthropogenic sources; and in green for (f) natural sources. The solid and dotted black lines represent the mean and min-max range (respectively) of the bottom-up estimates: anthropogenic inventories in (e) and ensemble of wetland models in (f). The vertical scale is divided by 2 for the mid-latitude and boreal regions.

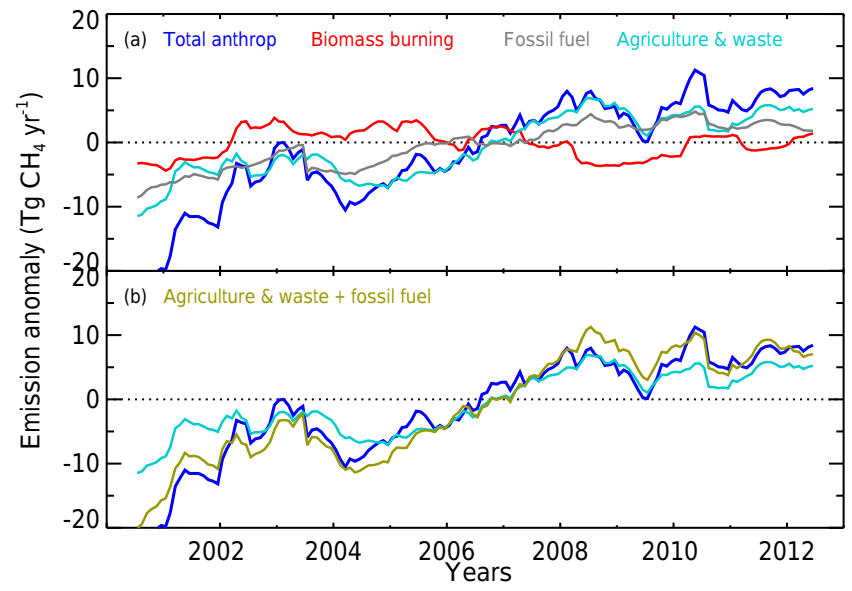

Figure 3. The 12-month running mean of global annual methane anthropogenic emission anomalies $\left(\mathrm{Tg} \mathrm{CH}_{4} \mathrm{yr}^{-1}\right)$ inferred by the ensemble of inversions (only mean values of the ensemble are represented) for (a) total anthropogenic, biomass burning, fossil fuel, and agriculture and waste sources. On the (b) panel, total anthropogenic, and agriculture and waste source anomalies are recalled on top of the sum of the anomalies from agriculture, waste, and fossil fuels sources.

Fig. 1b). Since 2007, methane atmospheric mole fraction rose again, reaching $1820 \mathrm{ppb}$ in 2012 . A mean growth rate of $5.2 \pm 0.2 \mathrm{ppb} \mathrm{yr}^{-1}$ over the period 2008-2012 is observed (Fig. 1b).

\subsubsection{Global emission changes in individual inversions}

As found in several studies (e.g. Bousquet et al., 2006), the flux anomaly (see Supplement, Sect. 2) from top-down inversions (Fig. 1d) is found more robust than the total source estimate when comparing different inversions (Fig. 1c). The mean range between the inverse estimates of total global emissions (Fig. 1c) is of $35 \mathrm{Tg} \mathrm{CH}_{4} \mathrm{yr}^{-1}$ (14 to 54 over the years and inversions reported here); this means that the uncertainty in the total annual global methane emissions inferred by top-down approaches is about $6 \%\left(35 \mathrm{Tg} \mathrm{CH}_{4} \mathrm{yr}^{-1}\right.$ over $550 \mathrm{Tg} \mathrm{CH}_{4} \mathrm{yr}^{-1}$ ). It is to be noted that this rather good agreement between these estimates is linked with the associated rather small range of global sinks. Indeed, most inversions use similar methyl chloroform (MCF)-constrained $\mathrm{OH}$ fields and temperature fields. The three top-down studies spanning 2000 to 2012 (Table 1) show an increase of 15 to $33 \mathrm{Tg} \mathrm{CH}_{4} \mathrm{yr}^{-1}$ between 2000 and 2012 (Fig. 1d). Despite the increase in global methane emissions being of the order of magnitude of the range between the models, flux anomalies clearly show that all individual inversions infer an increase in methane emissions over the period 2000-2012 (Fig. 1d). The inversions using satellite observations included here mainly use GOSAT retrievals (starting from mid-2009), and only one inversion is constrained with SCIAMACHY column methane mole fractions (from 2003 but ending in 2012, dashed lines in Fig. 1d). On average, satellite-based inversions infer higher annual emissions than surface-based inversions $\left(+12 \mathrm{Tg} \mathrm{CH}_{4} \mathrm{yr}^{-1}\right.$ higher over 


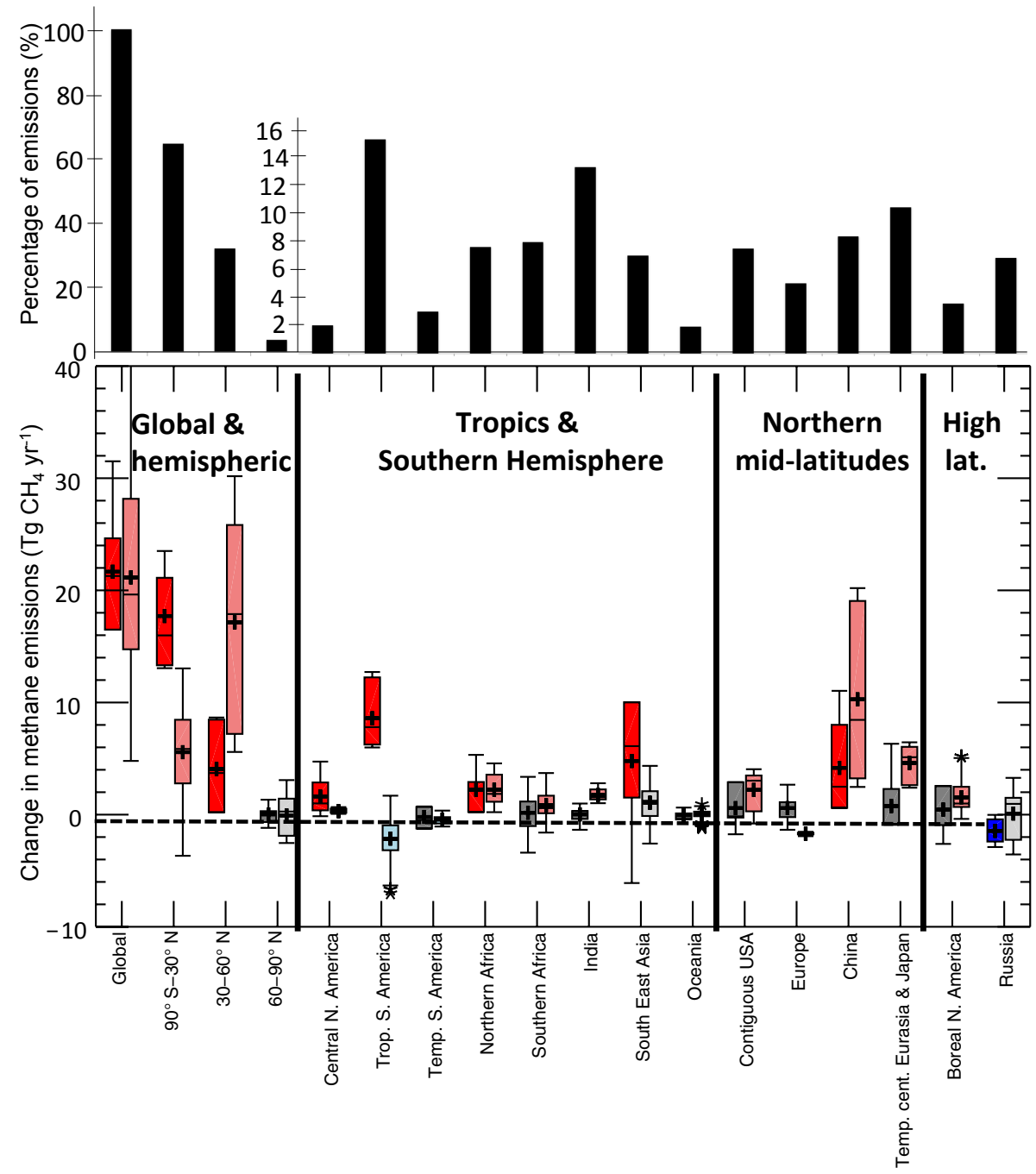

Figure 4. Top: contribution to the global methane emissions by region (in \%, based on the mean top-down estimates over 2003-2012 from Saunois et al., 2016). Bottom: changes in methane emissions over 2002-2006 and 2008-2012 at global, hemispheric, and regional scales in $\mathrm{TgCH}_{4} \mathrm{yr}^{-1}$. Red box plots indicate a significant positive contribution to emission changes (first and third quartiles above zero), blue box plots indicate a significant negative contribution to emission changes (first and third quartiles below zero), and grey box plots indicate not-significant emission changes. Dark coloured boxes are for top-down (five long inversions) and light coloured for bottom-up approaches (see text for details). The median is indicated inside each box plot (see Sect. 2). Mean values, reported in the text, are represented with "+" symbols. Outliers are represented with stars. (Note: the bottom-up approaches that provide country estimates - and not maps, USEPA and FAOSTAT - have not been processed to provide hemispheric values. As a result the ensemble used for the three hemispheric regions differs from the ensemble used for the global and regional estimates.)

2010-2012) as previously shown in Saunois et al. (2016) and Locatelli et al. (2015). Also, it is worth noting that the ensemble of top-down results shows emissions that are consistently lower in 2009 and higher in 2008 and 2010 (Figs. 1c and S1 in the Supplement).

\subsubsection{Year-to-year changes}

When averaging the anomalies in global emissions over the inversions, we find a difference of 22 [5-37] $\mathrm{Tg} \mathrm{CH}_{4}$ between the yearly averages for 2000 and 2012 (Fig. 2a). Over the period 2000-2012, the variations in emission anomalies reveal both year-to-year changes and a positive long-term trend. Year-to-year changes are found to be the largest in the tropics: up to $\pm 15 \mathrm{Tg} \mathrm{CH}_{4} \mathrm{yr}^{-1}$ (Fig. 2b), with a negative anomaly in 2004-2006 and a positive anomaly after 2007 visible in all inversions except one (Fig. 1d). Compared with the tropical signal, mid-latitude emissions exhibit smaller anomalies (mean anomaly mostly below $5 \mathrm{Tg}$ $\mathrm{CH}_{4} \mathrm{yr}^{-1}$, except around 2005) but contribute a rather sharp increase in 2006-2008, marking a transition between the period 2002-2006 and the period 2008-2012 at the global scale 
(Fig. 2a and c). The boreal regions do not contribute significantly to year-to-year changes, except in 2007 , as already noted in several studies (Dlugokencky et al., 2009; Bousquet et al., 2011).

When splitting global methane emissions into anthropogenic and natural emissions at the global scale (Fig. 2e and $f$, respectively), both of these two general categories show significant year-to-year changes. As natural and anthropogenic emissions occur concurrently in several regions, top-down approaches have difficulty in separating their contribution. Therefore the year-to-year variability allocated to anthropogenic emissions from inversions may be an artefact of our separation method (see Sect. 2) and/or reflect the larger variability between studies compared to natural emissions. However, some of the anthropogenic methane sources are sensitive to climate, such as rice cultivation or biomass burning, and also, to a lesser extent, enteric fermentation and waste management. Fossil fuel exploitation can also be sensitive to rapid economic changes, and meteorological variability may impact the fuel demand for heating and cooling systems. However, anthropogenic emissions reported by bottom-studies (black line on Fig. 2e) show much fewer year-to-year changes than inferred by top-down inversions (blue line of Fig. 2e). China coal production rose faster from 2002 until 2011, when its production started to stabilise or even decline (IEA, 2016). This last period is characterised by major reorganisations in the Chinese coal industry, including evolution from many small gassy mines to fewer mines with better safety and emission control. The global natural gas production steadily increased over time despite a short drop in production in 2009 following the economic crisis (IEA, 2016). The bottom-up inventories do reflect some of this variation, such as in 2009 when gas and oil methane emissions slightly decreased (EDGARv4.2FT2010 and EDGARv4.2EXT, Fig. S7). Methane emissions from agriculture and waste are continuously growing in the bottom-up inventories at the global scale. The observed activity data underlying the emissions from agriculture estimated in this study, as reported by countries to FAO via the FAOSTAT database (FAO, 2017a, b), exhibit inter-annual variabilities that partly explain the variability in methane emissions discussed herein. Livestock methane emissions from the Americas (mainly South America) increased mainly between 2000 and 2004 and remained stable afterwards (estimated by FAOSTAT, Fig. S12). Additionally, Asian (India, China, and South and East Asia) livestock emissions mainly increased between 2004 and 2008 and also remained rather stable afterwards. In contrast, livestock emissions in Africa increased continuously over the full period. These continental variations translate into global livestock emissions increasing continuously over the full period, though at a slower rate after 2008 (Fig. S13). Overall, these anthropogenic emissions exhibit more semi-decadal to decadal evolutions (see below) than year-to-year changes as found in top-down inversions.
For natural sources, the mean anomaly of the top-down ensemble suggests year-to-year changes ranging $\pm 10 \mathrm{Tg}$ $\mathrm{CH}_{4} \mathrm{yr}^{-1}$, which is lower than but in phase with the total source mean anomaly. The mean anomaly of global natural sources inferred by top-down studies is negative around 2005 and positive around 2007 (Fig. 2f). The year-to-year variation in wetland emissions inferred from land surface models is of the same order of magnitude but out of phase compared to the ensemble mean top-down estimates (Fig. 2f). However, some individual top-down approaches suggest anomalies smaller than or of different sign than the mean of the ensemble (Fig. S2). Also, some land surface models show anomalies in better agreement with the top-down ensemble mean in 2000-2006 (Fig. S11). The 2009 (2010) negative (positive) anomaly in wetland emissions is common to all land surface models (Fig. S11) and is the result of variations in flooded areas (mainly in the tropics) and in temperature (mainly in boreal regions) (Poulter et al., 2017). Overall, from the contradictory results from top-down and bottom-up approaches, it is difficult to draw any robust conclusions on the year-to-year variations in natural methane emissions over the period 2000-2012.

\subsubsection{Decadal trend}

The mean anomaly of the inversion estimates shows a positive linear trend in global emissions of $+2.2 \pm 0.2 \mathrm{Tg}$ $\mathrm{CH}_{4} \mathrm{yr}^{-2}$ over 2000-2012 Fig. 2a). It originates mainly from increasing tropical emissions $\left(+1.6 \pm 0.1 \mathrm{Tg} \mathrm{CH}_{4} \mathrm{yr}^{-2}\right.$, Fig. 2b) with a smaller contribution from the mid-latitudes $\left(+0.6 \pm 0.1 \mathrm{Tg} \mathrm{CH}_{4} \mathrm{yr}^{-2}\right.$, Fig. 2c). The positive global trend is explained mostly by an increase in anthropogenic emissions, as separated in inversions $\left(+2.0 \pm 0.1 \mathrm{Tg} \mathrm{CH}_{4} \mathrm{yr}^{-2}\right.$, Fig. 2e). This represents an increase of about $26 \mathrm{Tg} \mathrm{CH}_{4}$ in the annual anthropogenic emissions between 2000 and 2012 , casting serious doubt on the bottom-up methane inventories for anthropogenic emissions, showing an increase in anthropogenic emissions of +55 [45-73] $\mathrm{Tg} \mathrm{CH}_{4}$ between 2000 and 2012, with USEPA and GAINS inventories at the lower end and EDGARv4.2FT2012 at the higher end of the range. This possible overestimation of the recent anthropogenic emissions increase by inventories has already been suggested in individual studies (e.g. Patra et al., 2011; Bergamaschi et al., 2013; Bruhwiler et al., 2014; Thompson et al., 2015; Peng et al., 2016; Saunois et al., 2016) and is confirmed in this study as a robust feature. Splitting the anthropogenic sources into the components identified in the method section, the trend in anthropogenic emissions from top-down studies mainly originates from the agriculture and waste sector $\left(+1.2 \pm 0.1 \mathrm{Tg} \mathrm{CH}_{4} \mathrm{yr}^{-2}\right.$, Fig. 3a). Adding the fossil fuel emission trend almost matches the global trend of anthropogenic emissions (Fig. 3b). It should be noted here that the individual inversions all suggest constant to increasing emissions from agriculture and waste handling (Fig. S3), while some suggest constant to decreasing emissions from fossil 
fuel use and production (Fig. S4). The latter result seems surprising in view of large increases in coal production during 2000-2012, especially in China. However, this recent period is characterised by major reorganisations in the Chinese coal industry, including evolution from many small gassy mines to fewer mines with better safety and emission control. The trend in biomass burning emissions is small but barely significant between 2000 and $2012(-0.05 \pm 0.05 \mathrm{Tg}$ $\mathrm{CH}_{4} \mathrm{yr}^{-2}$, Fig. 3). This result is consistent with the GFED dataset (both versions 3 and $4 \mathrm{~s}$ ) for which no significant trend was found over this 13-year period. However, between 2002 and 2010, a significant negative trend of $-0.5 \pm 0.1 \mathrm{Tg}$ $\mathrm{CH}_{4} \mathrm{yr}^{-2}$ is found for biomass burning, both from the topdown approaches (Fig. S5) and the GFED3 and GFED4s inventory (Fig. S10); this corresponds to dry years in the tropics. Although it should be noted that almost all inversions use GFED3 in their prior fluxes (Table S1) and therefore are not independent from the bottom-up estimates Over the 13year period, the wetland emissions in the inversions show a small positive trend $\left(+0.2 \pm 0.1 \mathrm{Tg} \mathrm{CH}_{4} \mathrm{yr}^{-2}\right)$ about twice as large as the trends of emissions from land surface models but within the range of uncertainty $\left(+0.1 \pm 0.1 \mathrm{Tg} \mathrm{CH}_{4} \mathrm{yr}^{-2}\right.$, Poulter et al., 2017). As stated previously, the wetland emissions from some land surface models disagree with the ensemble mean of land surface models (Fig. S11).

\subsubsection{Quasi-decadal changes in the period 2000-2012}

According to Fig. 2a, the period 2000-2012 is split into two parts - before 2006 and after 2008. Neither a significant nor a systematic trend in the global total sources (among the inversions of Fig. 1d) is observed before 2006, likewise after 2008 (see Fig. S6 for individual calculated trends); although large year-to-year variations are visible. Before 2006, anthropogenic emissions show a positive trend of $+2.4 \pm 0.2 \mathrm{Tg}$ $\mathrm{CH}_{4} \mathrm{yr}^{-2}$, compensated for by decreasing natural emissions $\left(-2.4 \pm 0.2 \mathrm{Tg} \mathrm{CH}_{4} \mathrm{yr}^{-2}\right.$; calculated from Fig. 2e and f), which explains the rather stable global total emissions. Bousquet et al. (2006) discussed such compensation between 1999 and 2003. The behaviour of the top-down ensemble mean is consistent with a decrease in microbial emissions in 2000 2006, especially in the Northern Hemisphere as suggested by Kai et al. (2011) using ${ }^{13} \mathrm{CH}_{4}$ observations. However, Levin et al. (2012) showed that the isotopic data selection might bias this result, as they found no such decrease when using background site measurements. Indeed, some individual topdown studies still suggest constant emissions from both natural and anthropogenic sources (Figs. S2, S3 and S4) over that period as found by Levin et al. (2012) or Schwietzke et al. (2016), with both also using ${ }^{13} \mathrm{CH}_{4}$ observations. The different trends in anthropogenic and natural methane emissions among the inversions highlight the difficulties of the top-down approach in separating natural from anthropogenic emissions and also its dependence on prior emissions. All inversions are based on EDGAR inventory (most of them us- ing EDGARv4.2 version, Table S1). However, the estimated posterior anthropogenic emissions can significantly deviate from this common prior estimate. Similarly, inversions based on the same prior wetland fluxes do not systematically infer the same variations in methane total and natural emissions. These different increments from the prior fluxes are constrained by atmospheric observations and qualitatively indicate that inversions can depart from prior estimates. Contrary to the ensemble mean of inversions, the land surface models gathered in this study show on average a small positive trend $\left(+0.7 \pm 0.1 \mathrm{Tg} \mathrm{CH}_{4} \mathrm{yr}^{-2}\right)$ during 2000-2006 (calculated from Fig. 2f), with some exceptions in individuals models (Fig. S11). Recently, Schaefer et al. (2016), based on isotopic data, suggested that diminishing thermogenic emissions caused the early 2000 s plateau without ruling out variations in the $\mathrm{OH}$ sink. However, another scenario explaining the plateau could combine both constant total sources and sinks. Over 2000-2006, no decrease in thermogenic emissions is found in any of the inversions included in our study (Fig. S4). Even using time-constant prior emissions for fossil fuels in the inversions results in robustly inferring increasing fossil fuel emissions after 2000, although lower than when using inter-annually varying prior estimates from inventories (e.g. Bergamaschi et al., 2013).

All inversions show increasing emissions in the second half of the period, after 2006. For the period 2006-2012, most inversions show a significant positive trend (below $5 \mathrm{Tg}$ $\mathrm{CH}_{4} \mathrm{yr}^{-2}$ ), within $2 \sigma$ uncertainty for most of the available inversions (see Fig. S6). Most of this positive trend is explained by the years 2006 and 2007, due to both natural and anthropogenic emissions, but appears to be highly sensitive to the period of estimation (Fig. S6). Between 2008 and 2012, neither the total anthropogenic nor the total natural sources present a significant trend, leading to rather stable global total methane emissions (Fig. 2e and f). Overall, these results suggest that emissions shifted between 2006 and 2008 rather than continuously increasing after 2006 . The requirement of a step change in the emissions will be further discussed in Sect. 4. Because of this, in the following section, we analyse in more details the emission changes between two time periods: 2002-2006 and 2008-2012 at global and regional scales.

\subsection{The methane emission changes between 2002-2006 and 2008-2012}

\subsubsection{Global and hemispheric changes inferred by top-down inversions}

Integrating all inversions covering at least 3 years over each 5-year period, the global methane emissions are estimated at 545 [530-563] $\mathrm{Tg} \mathrm{CH}_{4} \mathrm{yr}^{-1}$ on average over 2002-2006 and at 569 [546-581] Tg $\mathrm{CH}_{4} \mathrm{yr}^{-1}$ over 2008-2012. It is worth noting some inversions do not contribute to both periods, leading to different ensembles being used to compute 
Table 3. Average methane emissions over 2002-2006 and 2008-2012 at the global, latitudinal, and regional scales in $\mathrm{Tg} \mathrm{CH}_{4} \mathrm{yr}^{-1}$, and differences between the periods 2008-2012 and 2002-2006 from the top-down and the bottom-up approaches. Uncertainties are reported as a [min-max] range of reported studies. Differences of $1 \mathrm{Tg} \mathrm{CH}_{4} \mathrm{yr}^{-1}$ in the totals can occur due to rounding errors. A minimum of 3 years was required to calculate the average value over the 5-year periods, and then the difference between the two periods was calculated for each approach. This means that 5 inversions are used to produce these values.

\begin{tabular}{lrrr|r}
\hline & & Top-down estimates & Bottom-up estimates \\
\hline Period & $2002-2006$ & $2008-2012$ & $2012-2008$ minus & $2012-2008$ minus \\
& & & $2002-2006$ & $2002-2006$ \\
\hline Global & $546[530-563]$ & $570[546-580]$ & $22[16-32]$ & $21[5-41]$ \\
\hline Latitudinal & & & & \\
$90^{\circ}$ S-30 N & $349[330-379]$ & $363[344-391]$ & $18[13-24]$ & $6[-4-13]$ \\
$30-60^{\circ} \mathrm{N}$ & $175[158-194]$ & $184[164-203]$ & $4[0-9]$ & $17[6-30]$ \\
$60-90^{\circ} \mathrm{N}$ & $20[14-24]$ & $22[15-31]$ & $0[-1-1]$ & $0[-3-3]$ \\
\hline Regional & & & & \\
Central North America & $10[3-15]$ & $11[6-16]$ & $2[0-5]$ & $0[0-1]$ \\
Tropical South America & $79[60-97]$ & $94[72-118]$ & $9[6-13]$ & $-2[-6-2]$ \\
Temperate South America & $17[12-27]$ & $15[12-19]$ & $0[-1-1]$ & $0[-1-0]$ \\
Northern Africa & $41[36-52]$ & $41[36-55]$ & $2[0-5]$ & $2[0-5]$ \\
Southern Africa & $44[37-54]$ & $45[36-59]$ & $0[-3-3]$ & $1[-2-4]$ \\
South and East Asia & $69[53-81]$ & $73[59-86]$ & $5[-6-10]$ & $1[-3-4]$ \\
India & $39[28-45]$ & $37[26-47]$ & $0[-1-1]$ & $2[1-3]$ \\
Oceania & $10[7-19]$ & $10[7-14]$ & $0[0-1]$ & $0[-1-1]$ \\
Contiguous USA & $42[37-48]$ & $42[33-48]$ & $1[-2-3]$ & $2[-1-4]$ \\
Europe & $27[21-35]$ & $29[22-36]$ & $1[-1-3]$ & $-2[-2-2]$ \\
Central Eurasia and Japan & $46[38-50]$ & $48[38-58]$ & $1[-1-6]$ & $5[2-6]$ \\
China & $53[47-62]$ & $56[41-73]$ & $4[1-11]$ & $10[2-20]$ \\
Boreal North America & $19[13-27]$ & $21[15-27]$ & $0[-3-3]$ & $2[0-5]$ \\
Russia & $39[32-45]$ & $38[30-44]$ & $-1[-3-0]$ & $0[-4-3]$ \\
\hline & & & & \\
\hline
\end{tabular}

Table 4. Mean values of the emission change (in $\mathrm{Tg} \mathrm{CH}_{4} \mathrm{yr}^{-1}$ ) between 2002-2006 and 2008-2012 inferred from the top-down and bottom-up approaches for the five general categories.

\begin{tabular}{lrr}
\hline & Top-down & Bottom-up \\
\hline Wetlands & $6[-4-16]$ & $-1[-8-7]$ \\
Agriculture and waste & $10[7-12]$ & $10[7-13]$ \\
Fossil fuels & $7[-2-16]$ & $17[11-25]$ \\
Biomass burning & $-3[-7-0]$ & $-2[-5-0]$ \\
Other natural & $2[-2-7]$ & - \\
\hline
\end{tabular}

these estimates. Despite the different ensembles (seven studies for 2002-2006 and 10 studies for 2008-2012), the estimate ranges for both periods are similar. Keeping only the five surface-based inversions covering both periods leads to 542 [530-554] $\mathrm{Tg} \mathrm{CH}_{4} \mathrm{yr}^{-1}$ on average over 2002-2006 and 563 [546-573] $\mathrm{Tg} \mathrm{CH}_{4} \mathrm{yr}^{-1}$ over 2008-2012, showing remarkably consistent values with the ensemble of the topdown studies and also not showing significant impact in the emission differences between the two time periods (see Table S3).
The emission changes between the period 2002-2006 and the period 2008-2012 have been calculated for inversions covering at least 3 years over both 5 -year periods (5 inversions) at global, hemispheric, and regional scales (Fig. 4). The regions are the same as in Saunois et al. (2016). The region denoted as " $90^{\circ} \mathrm{S}-30^{\circ} \mathrm{N}$ " is referred to as the tropics despite the southern mid-latitudes (mainly from Oceania and temperate South America) included in this region. However, since the extra-tropical Southern Hemisphere contributes less than $8 \%$ to the emissions from the " $90^{\circ} \mathrm{S}-30^{\circ} \mathrm{N}$ " region, the region primarily represents the tropics.

The global emission increase of +22 [16-32] $\mathrm{Tg} \mathrm{CH}_{4} \mathrm{yr}^{-1}$ is mostly tropical $\left(+18[13-24] \mathrm{Tg} \mathrm{CH}_{4} \mathrm{yr}^{-1}\right.$, or $\sim 80 \%$ of the global increase). The northern mid-latitudes only contribute an increase of +4 [0-9] $\mathrm{Tg} \mathrm{CH}_{4} \mathrm{yr}^{-1}$, while the highlatitudes (above $60^{\circ} \mathrm{N}$ ) contribution is not significant. However, most inversions rely on surface observations, which poorly represent the tropical continents, as previously noticed by a previous study (e.g. Bousquet et al., 2011). As a result, this tropical signal may partly be an artefact of inversions attributing emission changes to unconstrained regions. Also, the absence of a significant contribution from the Arctic region means that Arctic changes are below the detection 
limit of inversions. Indeed, the northern high latitudes emitted about 20 [14-24] Tg $\mathrm{CH}_{4} \mathrm{yr}^{-1}$ of methane over 20022006 and 22 [15-31] Tg $\mathrm{CH}_{4} \mathrm{yr}^{-1}$ over 2008-2012 (Table 3), but keeping inversions covering at least 3 years over each 5year period leads to a null emission change in boreal regions.

The geographical partition of the increase in emissions between 2000-2006 and 2008-2012 inferred here is in agreement with Bergamaschi et al. (2013), who found that 50$85 \%$ of the $16-20 \mathrm{Tg} \mathrm{CH}_{4}$ emission increase between $2007-$ 2010 and 2003-2005 came from the tropics and the rest from the Northern Hemisphere mid-latitudes. Houweling et al. (2014) inferred an increase of $27-35 \mathrm{Tg} \mathrm{CH}_{4} \mathrm{rr}^{-1}$ between the 2-year periods before and after July 2006. The ensemble of inversions gathered in this study infer a consistent increase of 30 [20-41] Tg $\mathrm{CH}_{4} \mathrm{yr}^{-1}$ between the same two periods. The derived increase is highly sensitive to the choice of the starting and ending dates of the time period. The study of Patra et al. (2016) based on six inversions found an increase of $19-36 \mathrm{Tg} \mathrm{CH}_{4} \mathrm{yr}^{-1}$ in global methane emissions between 2002-2006 and 2008-2012, which is consistent with our results.

\subsubsection{Regional changes inferred by top-down inversions}

At the regional scale, top-down approaches infer different emission changes both in amplitude and in sign. These discrepancies are due to transport errors in the models and to differences in inverse setups and can lead to several tens of per cent differences in the regional estimates of methane emissions (e.g. Locatelli et al., 2013). Indeed, the recent study of Cressot et al. (2016) showed that, while global and hemispheric emission changes could be detected with confidence by the top-down approaches using satellite observations, their regional attribution is less certain. Thus, it is particularly critical for regional emissions to rely on several inversions, as done in this study, before drawing any robust conclusion. In most of the top-down results (Fig. 4), the tropical contribution to the global emission increase originates mainly in tropical South America (+9 [6-13] $\mathrm{Tg} \mathrm{CH}_{4} \mathrm{yr}^{-1}$ ) and South and East Asia $\left(+5[-6-10] \mathrm{Tg} \mathrm{CH}_{4} \mathrm{yr}^{-1}\right)$. Central North America (+2 [0-5] Tg $\left.\mathrm{CH}_{4} \mathrm{yr}^{-1}\right)$ and northern Africa (+2 [0-5] $\mathrm{Tg} \mathrm{CH}_{4} \mathrm{yr}^{-1}$ ) contribute less to the tropical emission increase. The sign of the contribution from South and East Asia is positive in most studies (e.g. Houweling et al., 2014), although some studies infer decreasing emission in this region. The disagreement between inversions could result from the lack of measurement stations to constrain the fluxes in Asia (some have appeared inland India and China but only in the last years, Lin et al., 2017), and also from the rapid up-lift of the compounds emitted at the surface to the free troposphere by convection in this region, leading to surface observations missing information on local fluxes (e.g. Lin et al., 2015).

In the northern mid-latitudes a positive contribution is inferred for China (+4 [1-11] Tg $\mathrm{CH}_{4} \mathrm{yr}^{-1}$ ) and Central Eura- sia and Japan $\left(+1 \quad[-1-6] \mathrm{Tg} \mathrm{CH}_{4} \mathrm{yr}^{-1}\right)$. Also, temperate North America does not contribute significantly to the emission changes. Contrary to a large increase in the US emissions suggested by Turner et al. (2016), none of the inversions detect, at least prior to 2013, an increase in methane emissions possible due to increasing shale gas exploitation in the US. Bruhwiler et al. (2017) highlight the difficulty of deriving trends on relatively short term due to, in particular, inter-annual variability in transport.

The inversions agree that emissions changes remained limited in the Arctic region but do not agree on the sign of the emission change over the high northern latitudes, especially over boreal North America; however, they show a consistent small emission decrease in Russia. This lack of agreement between inversions over the boreal regions highlights the weak sensitivity of inversions in these regions where no or little methane emission changes are found to have occurred over the last decade. Changes in wetland emissions associated with sea ice retreat in the Arctic are probably only a few Tg between the 1980s and the 2000s (Parmentier et al., 2015). Also, decreasing methane emissions in subArctic areas that were drying and cooling over 2003-2011 have offset increasing methane emissions in a wetting Arctic and warming summer (Watts et al., 2014). Permafrost thawing may have caused additional methane production underground (Christensen et al., 2004), but changes in the methane flux to the atmosphere have not been detected by continuous atmospheric stations around the Arctic, despite a small increase in late autumn-early winter in methane emission from Arctic tundra (Sweeney et al., 2016). However, unintentional double counting of emissions from different water systems (wetlands, rivers, lakes) may lead to Artic emission growth in the bottom-up studies when little or none exists (Thornton et al., 2016). The detectability of possibly increasing methane emissions from the Arctic seems possible today based on the continuous monitoring of the Arctic atmosphere at a few but key stations (e.g. Berchet et al., 2016; Thonat et al., 2017), but this surface network remains fragile in the long term and would be more robust with additional constraints such as those that will be provided in 2021 by the active satellite mission MERLIN (Pierangello et al., 2016; Kiemle et al., 2014).

\subsubsection{Emission changes in bottom-up studies}

The top-down approaches use bottom-up estimates as a priori values. For anthropogenic emissions, most of them use the EDGARv4.2FT2010 inventory and GFED3 emission estimates for biomass burning. Their source of a priori information differs more for the contribution from natural wetlands, geological emissions, and termite sources (Table S1). Here we gathered an ensemble of bottom-up estimates for the changes in methane emissions between 2000-2006 and 2008-2012, combining anthropogenic inventories (EDGARv4.2FT2010, USEPA, and GAINS), five 
biomass burning emission estimates (GFED3, GFED4s, FINN, GFAS, and FAOSTAT), and wetland emissions from 11 land surface models (see Sect. 2 for the details and Saunois et al., 2016 and Poulter et al., 2017). As previously stated, other natural methane emissions (termites, geological, inland waters) are assumed in these model studies to not contribute significantly to the change between 2000-2006 and 2008-2012, because no quantitative indications are available on such changes and because at least some of these sources are less climate sensitive than wetlands.

The bottom-up estimate of the global emission change between the periods 2000-2006 and 2008-2012 (+21 [541] $\mathrm{Tg} \mathrm{CH}_{4} \mathrm{yr}^{-1}$, Fig. 4) is comparable but possesses a larger spread than top-down estimates $(+22$ [16-32] Tg $\mathrm{CH}_{4} \mathrm{yr}^{-1}$ ). Also, the hemispheric breakdown of the change reveals discrepancies between top-down and bottom-up estimates. The bottom-up approaches suggest a much higher increase in emissions in the mid-latitudes $(+17$ [6-30] Tg $\mathrm{CH}_{4} \mathrm{yr}^{-1}$ ) than inversions and a smaller increase in the tropics (+6 [-4-13] Tg $\left.\mathrm{CH}_{4} \mathrm{yr}^{-1}\right)$. The main regions where bottom-up and top-down estimates of emission changes differ are tropical South America, South and East Asia, China, USA, and central Eurasia and Japan.

While top-down studies indicate a dominant increase between 2000-2006 and 2008-2012 in tropical South America (+9 [6-13] $\mathrm{Tg} \mathrm{CH}_{4} \mathrm{yr}^{-1}$ ), the bottom-up estimates (based on an ensemble of 11 land surface models and anthropogenic inventories), in contrast, indicate a small decrease (-2 [-6-2] $\mathrm{Tg} \mathrm{CH}_{4} \mathrm{yr}^{-1}$ ) over the same period (Fig. 4). The decrease in tropical South American emissions found in the bottomup studies results from decreasing emissions from wetlands (about $-2.5 \mathrm{Tg} \mathrm{CH}_{4} \mathrm{yr}^{-1}$, mostly due to a reduction in tropical wetland extent, as constrained by the common inventory used by all models, see Poulter et al., 2017) and biomass burning (about $-0.7 \mathrm{Tg} \mathrm{CH}_{4} \mathrm{yr}^{-1}$ ), partly compensated for by a small increase in anthropogenic emissions (about $1 \mathrm{Tg}$ $\mathrm{CH}_{4} \mathrm{yr}^{-1}$, mainly from agriculture and waste). Most of the top-down studies infer a decrease in biomass burning emissions over this region, exceeding the decrease in a priori emissions from GFED3. Thus, the main discrepancy between top-down and bottom-up is due to microbial emissions from natural wetlands (about $4 \mathrm{Tg} \mathrm{CH}_{4} \mathrm{yr}^{-1}$ on average), agriculture, and waste (about $2 \mathrm{Tg} \mathrm{CH}_{4} \mathrm{yr}^{-1}$ on average) over tropical South America.

The emission increase in South and East Asia for the bottom-up estimates $\left(2 \mathrm{Tg} \mathrm{CH}_{4} \mathrm{yr}^{-1}\right.$ ) results from a $4 \mathrm{Tg}$ $\mathrm{CH}_{4} \mathrm{yr}^{-1}$ increase (from agriculture and waste for half of it, fossil fuel for one-third, and wetland for the remainder) offset by a decrease in biomass burning emissions $(-2[-4-$ 0] $\mathrm{Tg} \mathrm{CH}_{4} \mathrm{yr}^{-1}$ ). The inversions suggest a higher increase in South and East Asia compared to this $2 \mathrm{Tg} \mathrm{CH}_{4} \mathrm{yr}^{-1}$, mainly due to higher increases in wetland and agriculture and waste sources, with the biomass burning decrease and the fossil fuel increase being similar in the inversions compared to the inventories.

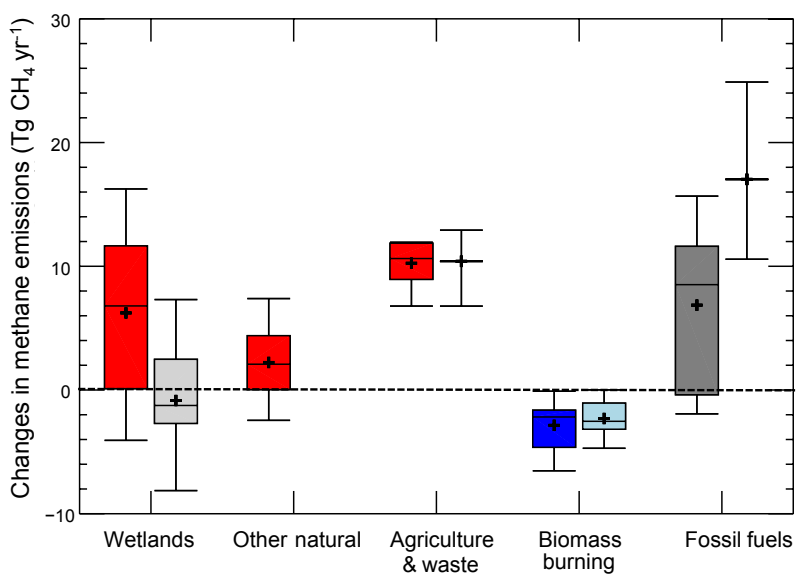

Figure 5. Changes in methane emissions between 2002-2006 and 2008-2012 in $\mathrm{Tg} \mathrm{CH}_{4} \mathrm{yr}^{-1}$ for the five source types. Red box plots indicate a significant positive contribution to emission changes (first and third quartiles above zero), blue box plots indicate a significant negative contribution to emission changes (first and third quartiles below zero), and grey box plots indicate non-significant emission changes. Dark (light) coloured boxes are for top-down (bottom-up) approaches (see text for details). The median is indicated inside each box plot (see Methods, Sect. 2). Mean values, reported in the text, are represented with "+" symbols.

In tropical South America and South and East Asia, wetlands and agriculture and waste emissions may both occur in the same or neighbouring model pixels, making the partitioning difficult for the top-down approaches. Also, these two regions lack surface measurement sites, so the inverse systems are less constrained by the observations. However, the SCIAMACHY-based inversion from Houweling et al. (2014) also infers increasing methane emissions over tropical South America between 2002-2006 and 2008-2012. Further studies based on satellite data or additional regional surface observations (e.g. Basso et al., 2016; Xin et al., 2015) would be needed to better assess methane emissions (and their changes) in these under-sampled regions.

For China, bottom-up approaches suggest a +10 [2-20] Tg $\mathrm{CH}_{4} \mathrm{yr}^{-1}$ emission increase between 2002-2006 and 20082012 , i.e. a trend of about $1.7 \mathrm{Tg} \mathrm{CH}_{4} \mathrm{yr}^{-2}$ (considering a $10 \mathrm{Tg} \mathrm{yr}^{-1}$ increase over 2004-2010), which is much larger than the top-down estimates. The magnitude of the Chinese emission increase varies among emission inventories and essentially appears to be driven by an increase in anthropogenic emissions (fossil fuel and agriculture and waste emissions). Anthropogenic emission inventories indicate that Chinese emissions increased at a rate of $0.6 \mathrm{Tg} \mathrm{CH}_{4} \mathrm{yr}^{-2}$ in USEPA, $3.1 \mathrm{Tg} \mathrm{yr}^{-2}$ in EDGARv4.2, and $1.5 \mathrm{Tg} \mathrm{CH}_{4} \mathrm{yr}^{-2}$ in GAINS between 2000 and 2012. The increase rate in EDGARv4.2 is too strong compared to a recent bottom-up study that suggests a $1.3 \mathrm{Tg} \mathrm{CH} \mathrm{CH}^{-2}$ increase in Chinese methane emissions over 2000-2010 (Peng et al., 2016). The revised EDGAR inventory v4.3.2 (not officially released when we 
write these lines) with region-specific emission factors for coal mining in China gives a mean trend in coal emissions of 1.0 Tg $\mathrm{CH}_{4} \mathrm{yr}^{-2}$ over 2000-2010, which is half the value from the previous version EDGARv4.2FT2010 (Fig. S14). These new estimates are more in line with USEPA inventory and with the top-down approaches (range of 0.3 to $2.0 \mathrm{Tg}$ $\mathrm{CH}_{4} \mathrm{yr}^{-2}$ for the total sources in China over 2000-2012), in agreement with Bergamaschi et al. (2013) who inferred an increase rate of $1.1 \mathrm{Tg} \mathrm{CH}_{4} \mathrm{yr}^{-2}$ over 2000-2010.

Finally, while bottom-up approaches show a small increase in US emissions $\left(+2[-1-4] \mathrm{Tg} \mathrm{CH}_{4} \mathrm{yr}^{-1}\right)$, top-down studies do not show any significant emission change, and this result holds similarly for central Eurasia and Japan.

\subsubsection{Emission changes by source types}

In Sect. 3.1, we suggest that a concurrent increase in both natural and anthropogenic emissions over 2006-2008 contribute to the total emission increase between 2002-2006 and 2008-2012. The attribution of this change to different source types remains uncertain in inversions, as methane observations alone do not provide sufficient information to fully separate individual sources (see Introduction). However, as in Saunois et al. (2016), we present here a sectorial view of methane emissions for five general source categories, limited at the global scale (Fig. 5, Table 4), as the regional attribution of emission increase is considered too uncertain (Saunois et al., 2016; Tian et al., 2016).

The top-down studies show a dominant positive contribution from microbial sources, such as agriculture and waste (+10 [7-12] $\mathrm{Tg} \mathrm{CH}_{4} \mathrm{yr}^{-1}$ ), and natural wetlands (+6 [-416] $\mathrm{Tg} \mathrm{CH}_{4} \mathrm{yr}^{-1}$ ) as compared to fossil-fuel-related emissions (+7 [-2-16] $\left.\mathrm{Tg} \mathrm{CH}_{4} \mathrm{yr}^{-1}\right)$. Biomass burning emissions decreased $\left(-3[-7-0] \mathrm{Tg} \mathrm{CH}_{4} \mathrm{yr}^{-1}\right)$. Other natural sources show a lower but significant increase $(+2 \quad[-2-$ 7] $\mathrm{Tg} \mathrm{CH}_{4} \mathrm{yr}^{-1}$ ). These values are estimated based on the five longest inversions. Taking into account shorter inversions leads to different minimum and maximum values, but the mean values are quite robust (Table S4).

Wetland emission changes estimated by 11 land surface models from Poulter et al. (2017) are near zero, but the stability of this source is statistically consistent with the top-down value considering the large uncertainties of both top-down inversions and bottom-up models (Sects. 3.1 and 4). It is worth noting that, for wetland prior estimates, top-down studies generally rely on climatology from bottom-up approaches (e.g. Matthews and Fung, 1987; Kaplan, 2002) and therefore the inferred trend are more independent from bottom-up models than anthropogenic estimates, which generally rely on inter-annually prescribed prior emissions.

The bottom-up estimated decrease in biomass burning emissions of $\left(-2[-5-0] \mathrm{Tg} \mathrm{CH}_{4} \mathrm{yr}^{-1}\right)$ is consistent with top-down estimates, albeit smaller. The change in agriculture and waste emissions between 2002-2006 and 2008-2012 in the bottom up inventories is in agreement with the top-down values (+10 [7-13] $\mathrm{Tg} \mathrm{CH}_{4} \mathrm{yr}^{-1}$ ), with about two-third of this being increase from agriculture activities (mainly enteric fermentation and manure management, while rice emissions were fairly constant between these two time periods) and one-third from waste (Table S5). The spread between inventories in the increase in methane emissions from the waste sector is much lower than from agriculture activities (enteric fermentation, manure management, and rice cultivation) (see Table S5). Considering livestock (enteric fermentation and manure) emissions estimated by FAOSTAT, about half of the global increase between 2002-2006 and 2008-2012 originates from Asia (India, China, and South and East Asia) and one-third from Africa.

The changes in fossil-fuel-related emissions in bottom-up inventories between 2002-2006 and 2008-2012 (+17 [1125] $\mathrm{Tg} \mathrm{CH}_{4} \mathrm{yr}^{-1}$ ) are more than twice the estimate from the top-down approaches $\left(+7[-2-16] \mathrm{Tg} \mathrm{CH}_{4} \mathrm{yr}^{-1}\right)$. Among the inventories, EDGARv4.2 stands in the higher range, with fossil-fuel-related emissions increasing twice as fast as in USEPA and GAINS. The main contributors to this discrepancy are the emissions from coal mining, which increase 3 times as fast as in EDGARv4.2 than in the two other inventories at the global scale. About half of the global increase in fossil fuel emissions originates from China in the EDGARv4.2 inventory. Thus, most of the difference between top-down and bottom-up originates from coal exploitation estimates in China, which is likely overestimated in EDGARv4.2 as aforementioned (Bergamaschi et al., 2013; Peng et al., 2016; Dalsoren et al., 2016; Patra et al., 2016; Saunois et al., 2016). The release of EDGARv4.3.2 will, at least partly, close the gap between top-down and bottom-up studies. Indeed, in EDGARv4.3.2 coal emissions in China increase by $4.3 \mathrm{Tg} \mathrm{CH}_{4} \mathrm{yr}^{-1}$ between 2002-2006 and 20082010 instead of $9.7 \mathrm{Tg} \mathrm{CH}_{4} \mathrm{yr}^{-1}$ in EDGARv4.2FT2010, due to the revision of coal emission factors in China. As a result, the next release of EDGARv4.3.2 should narrow the range and decrease the mean contribution of fossil fuels to emission changes estimated by the bottom-up studies.

\section{Discussion}

The top-down results gathered in this synthesis suggest that the increase in methane emissions between 2002-2006 and 2008-2012 is mostly tropical, with a small contribution from the mid-latitudes, and is dominated by an increase in microbial sources, more from agriculture and waste $(+10$ [712] $\mathrm{Tg} \mathrm{CH}_{4} \mathrm{yr}^{-1}$ ) than wetlands, with the latter being uncertain (+6 [-4-16] Tg $\mathrm{CH}_{4} \mathrm{yr}^{-1}$ ). The contribution from fossil fuels to this emission increase is uncertain but smaller on average $\left(+7[-2-16] \mathrm{Tg} \mathrm{CH}_{4} \mathrm{yr}^{-1}\right)$. These increases in methane emissions are partly counterbalanced by a decrease in biomass burning emissions $\left(-3[-7-0] \mathrm{Tg} \mathrm{CH}_{4} \mathrm{yr}^{-1}\right)$. These results are in agreement with the top-down studies of Bergamaschi et al. (2013) and Houweling et al. (2014), 


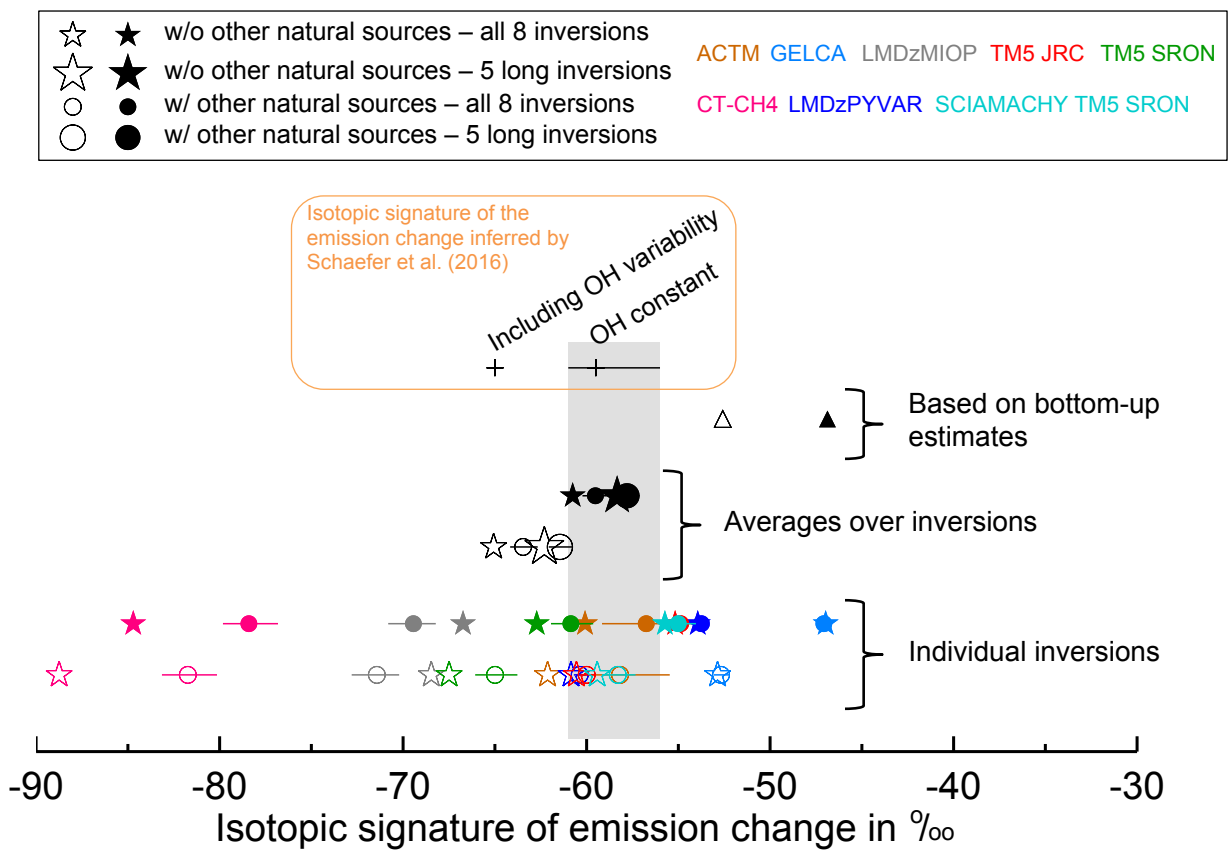

Figure 6. Isotopic signature (in \%o) of the emission change between 2002-2006 and 2008-2012 based on Eq. (1) and the isotopic source signatures from Schaefer et al. (2016) and Schwietzke et al. (2016) in filled and open symbols, respectively. The range of the isotopic signature of the emission change derived by the box model of Schaefer et al. (2016) is indicated as the grey shaded area when assuming constant $\mathrm{OH}$. The isotopic signatures derived from the ensemble of bottom-up estimates are shown with a triangle symbol. The individual inversions are shown in colour. The mean inversion estimates are shown with circles and stars, taking and without taking into account the "other natural" sources, respectively. The range around the circle indicates the range due to the choice of the isotopic source signature for the "other natural" source between -40 and $-57 \%$ (see text).

though there are some discrepancies between inversions in the regional attribution of the changes in methane emissions. The sectorial partitioning from inversions is in agreement (within the uncertainty) with bottom-up inventories (noting that inversions are not independent from inventories). However, the top-down ensemble significantly decreases the methane emission change from fossil fuel production and use compared to the bottom-up inventories. In the coming years, the revised version of the EDGAR inventory (see Sect. 3.2.4) should decrease the estimated change by bottom-up inventories, reducing the difference between bottom-up and topdown estimates.

\subsection{Wetland contribution}

The increasing emissions from natural wetlands inferred from the top-down approaches are not consistent with the average of the land surface models from Poulter et al. (2017). Bloom et al. (2010) found that wetland methane emissions increased by $7 \%$ over $2003-2007$ mainly due to warming in the mid-latitudes and Arctic regions and that tropical wetland emissions remained constant over this period. Increases of $2[-1-5] \mathrm{Tg} \mathrm{CH}_{4} \mathrm{yr}^{-1}$ and of $1[0-2] \mathrm{Tg} \mathrm{CH}_{4} \mathrm{yr}^{-1}$ between 2002-2006 and 2008-2012 are inferred from the 11 land surface models over the northern mid-latitudes and bo- real regions, respectively (Table $\mathrm{S} 7$, linked to temperature increase). Decreasing wetland emissions in the tropics (mostly due to reduced wetland extent) in the land surface models $\left(-3[-8-0] \mathrm{Tg} \mathrm{CH}_{4} \mathrm{yr}^{-1}\right.$ ) offset the mid-latitude and boreal increases, resulting in stable emissions between 2002-2006 and 2008 at the global scale. These different conclusions between inversions and wetland models highlight the difficulties in estimating wetland methane emissions (and their changes). The range of the methane emissions estimated by land surface models driven with the same flooded area extent shows that the models are highly sensitive to the wetland extent, temperature, precipitation, and atmospheric $\mathrm{CO}_{2}$ feedbacks (Poulter et al., 2017). The JULES land model used by McNorton et al. (2016b) is one of the three models inferring slightly higher emissions in 2008-2012 than 20022006 from the ensemble used in our study (Table S6). However, they found larger increases in northern mid-latitude wetland emissions and near zero change in tropical wetland emissions, in contrast to the atmospheric inversions. The exponential temperature dependency of methanogenesis through microbial production has been recently revised upwards (Yvon-Durocher et al., 2014). Accounting for this revision, smaller temperature increases are needed to explain large methane emission changes in warm climate (such as in the tropics; Marotta et al., 2014). However, no significant 
trend in tropical surface temperature is inferred over 20002012 that could explain an increase in tropical wetland emissions (Poulter et al., 2017). Methane emissions are also sensitive to the extent of the flooded area and for non-flooded wetlands and to the depth of the water table (Bridgham et al., 2013). The recurrent La Niña conditions from 2007 (compared to more El Niño conditions in the beginning of the 2000s) may have triggered wetter conditions propitious to higher methane emissions in the tropics (Nisbet et al., 2016). Indeed, both the flooded dataset used in Poulter et al. (2017) and the one used in Mc Norton et al. (2016b) based on an improved version of the topography-based hydrological model (Marthews et al., 2015) show decreasing wetland extents from the 2000s to the 2010s. However, resulting decreasing methane emissions are not in agreement with top-down studies even when constrained by satellite data. Thus, as has been concluded in most land model $\mathrm{CH}_{4}$ inter-comparisons and analyses, more efforts are needed to better assess the wetland extent and its variations (e.g. Bohn et al., 2015; Melton et al., 2013; Xu et al., 2016). Even though top-down approaches may attribute the emissions increase between 2002-2006 and 2008-2012 to tropical regions (and hence partly to wetland emitting areas) due to a lack of observational constraints, it is not possible, with the evidence provided in this study, to rule out a potential positive contribution of wetland emissions in the increase in global methane emissions at the global scale.

\subsection{Isotopic constraints}

The recent variation in atmospheric methane mole fractions has been widely discussed in the literature in relation to concurrent methane isotopes. Schaefer et al. (2016) tested several scenarios of perturbed methane emissions to fit both atmospheric methane and $\delta^{13} \mathrm{C}-\mathrm{CH}_{4}$. For the post-2006 period (2007-2014), they found that an average emission increase of $19.7 \mathrm{Tg} \mathrm{CH}_{4} \mathrm{yr}^{-1}$ with an associated isotopic signature of about $-59 \%$ o ( -61 to $-56 \%$ o ) is needed to match both $\mathrm{CH}_{4}$ and $\delta{ }^{13} \mathrm{C}_{-} \mathrm{CH}_{4}$ observed trends. After assigning an isotopic signature $\left(\delta_{i}\right)$ of each source contribution to the change $\left(\Delta E_{i}\right)$, it is possible to estimate the average isotopic signature of the emission change $\left(\delta_{\text {ave }}\right)$ as the weighted mean of the isotopic signature of all the sources contributing to the change, following Eq. (1):

$\delta_{\mathrm{ave}}=\frac{1}{\sum_{i} \Delta E_{i}} \sum_{i} \delta_{i} \Delta E_{i}$.

However, assigning an isotopic signature to a specific source remains a challenge due to sparse sampling of the different sources and wide variability of the isotopic signature of each given source: for example, methane emissions from coal mining have a range of -70 to $-30 \%$ in $\delta^{13} \mathrm{C}$ $\mathrm{CH}_{4}$ (Zazzeri et al., 2016; Schwietzke et al., 2016). The difficulty increases when trying to assign an isotopic signature to a broader category of methane sources at the global scale. Schaefer et al. (2016) suggest the following global mean isotopic signatures: $-60 \%$ for microbial sources (wetland, agriculture and waste), $-37 \%$ for thermogenic (fossil fuel sources), and $-22 \%$ for pyrogenic (biomass burning emissions); while a recent study suggests different globally averaged isotopic signatures (Sherwood et al., 2017), with a lighter fossil fuel signature: $-44 \%$ o for fossil fuels, $-62 \%$ o for microbial, and $-22 \%$ for biomass burning emissions (Schwietzke et al., 2016). Also, there is the question of the isotopic signature to be attributed to "other natural" sources that include geological emissions $(\sim-49 \%$, Etiope, 2015), termites ( $\sim 57 \%$, Houweling et al., 2000), or oceanic sources ( $\sim-40 \%$, Houweling et al., 2000). Applying either set of isotopic signatures to the bottom-up estimates of methane emission changes leads, as expected, to unrealistically heavy $\delta^{13} \mathrm{CH}_{4}$ signatures due to large changes in fossil fuel emissions (Fig. 6). Most of the individual inversions do not agree with the atmospheric isotopic change between 2002-2006 and 2008-2012 (Fig. 6), due to their large increases in fossil fuel or wetland emissions and/or large decrease in biomass burning emissions (Table S4). Most of the inverse systems solve only for total net methane emissions making the sectorial partition uncertain and dependent on the prior partitioning. However, applying Schaefer et al. (2016) isotopic source signatures to the mean emission changes derived from the ensemble of inversions (Table 4) in Eq. (1) leads to an average isotopic signature of the emission change well in agreement with the range of Schaefer et al. (2016), no matter which choice is made for the "other natural" sources or the number of inversions selected (Fig. 6). Applying the Schwietzke et al. (2016) isotopic source signatures leads to a lighter average isotopic signature of the emission change - in the higher range (in absolute value) of Schaefer et al. (2016). In short, the isotopic signature of the emissions change between 2002-2006 and 2008-2012 derived from the ensemble mean of inversions seems consistent with ${ }^{13} \mathrm{C}$ atmospheric signals. However, the uncertainties of these mean emission changes remain very large, as shown by the range inferred by inversions. Also, the deviations of most of the individual inversions from the ensemble mean highlight the sensitivity of the atmospheric isotopic signal to the changes in methane sources. To conclude, isotopic studies such as Schaefer et al. (2016) can help eliminate combinations of sources that are unrealistic, but they cannot point towards a unique solution. This problem has more unknowns than constraints, and other pieces of information need to be added to further solve it (such as ${ }^{14} \mathrm{C}$, deuterium, or co-emitted species, but also better latitudinal information, especially in the tropics).

\subsection{Oil and gas emissions and ethane constraint}

Co-emitted species with methane, such as ethane from fugitive gas leaks, can also help in assessing contributions from oil and gas sources. Indeed, Haussmann et al. (2016) used ethane to methane emission ratios to estimate the contri- 
bution from oil and gas emissions to the recent methane increase. For 2007-2014, their emission optimisation suggests that total methane emissions increased by $24-45 \mathrm{Tg}$ $\mathrm{CH}_{4} \mathrm{yr}^{-1}$, which is larger than in our study (Sect. 3.2.1), but the time period covered only partially overlaps with our study and they use a different method. Assuming a linear trend over 2007-2014 leads to an increase of 18-34 $\mathrm{Tg} \mathrm{CH}_{4} \mathrm{yr}^{-1}$ over 2007-2012. The Haussmann et al. (2016) reference scenario assumes that a mixture of oil and gas sources contributed at least $39 \%$ of the increase in total emissions, corresponding to an increase in oil and gas methane emissions of 7$13 \mathrm{Tg} \mathrm{CH}_{4} \mathrm{yr}^{-1}$ over 2007-2012. Adding up the increase in methane emissions from coal mining (USEPA suggests a $4 \mathrm{Tg} \mathrm{CH}_{4} \mathrm{yr}^{-1}$ increase between 2002-2006 and 2008-2012, Table S5) would lead to an increase in fossil fuel emission in the upper range of the top-down estimates presented here (7 [-2-16] Tg $\mathrm{CH}_{4} \mathrm{yr}^{-1}$ ). Helmig et al. (2016), using an ethane to methane emission ratio of $10 \%$ and assuming it constant, calculated an increase of $4.4 \mathrm{Tg} \mathrm{CH}_{4} \mathrm{yr}^{-1}$ each year during 2009-2014, which leads to a cumulative increase that is inconsistent in regards to both the global atmospheric isotopic signal and the observed leak rates in productive regions. Ethane to methane emission ratios are uncertain (ranging 7.1 to $16.2 \%$ in the Haussmann et al., 2016, reference scenario and 16.2 to $32.4 \%$ in their pure oil scenario) and could experienced variations (e.g. Wunch et al., 2016) that are not taken into account due to lack of information. Indeed, ethane to methane emission ratios also largely depend on the shale formation, and considering a too-low ethane to methane emission ratio could lead to erroneously too-large methane emissions from shale gas (Kort et al., 2016). In addition, the recent bottom-up study of Höglund-Isaksson (2017) shows relatively stable methane emissions from oil and gas after 2007 , due to increases in the recovery of associated petroleum gas (particularly in Russia and Africa) that balances an increase in methane emissions from unconventional gas production in North America.

Overall, the mean emission changes resulting from the top-down approach ensemble agree well with the isotopic atmospheric observations, but further studies (inversions and field measurements) would be needed to consolidate the (so far) weak agreement with the ethane-based global studies. Better constraints on the relative contributions of microbial emissions and thermogenic emissions derived from the topdown approaches using both isotopic observations and additional measurements such as ethane (with more robust emission ratios to methane) or other hydrocarbons (Miller et al., 2012) would help improve the ability to separate sources using top-down inversions.

\subsection{Methane sink by $\mathrm{OH}$}

As stated in Sect. 2, this paper focuses on methane emission changes. The methane sinks, especially $\mathrm{OH}$ oxidation, can also play a role in the methane budget changes. How- ever, the results from the inversions presented here, for most of them, assume constant $\mathrm{OH}$ concentrations over the period 2000-2012 (though including seasonal variations, Table $\mathrm{S} 2$ ). The methane loss due to these climatological $\mathrm{OH}$ is still computed using the meteorology-driven chemical rate in all models. Before 2007, increasing OH concentrations could have contributed to the stable atmospheric methane burden in this period (Dalsøren et al., 2016), without (or with less of) a need for constant global emissions. Including $\mathrm{OH}$ variability in their tests, Schaefer et al. (2016) found that $\mathrm{CH}_{4}$ variations can be explained only up to 2008 by changes in $\mathrm{OH}$ only and that an isotopic signature of the total additional source of $-65 \%$ is necessary to explain the $\delta^{13} \mathrm{C}-\mathrm{CH}_{4}$ observations (see their supplementary materials). However, a $-65 \%$ isotopic signature of additional emissions would require fewer changes from fossil fuel emissions or more changes from microbial sources than inferred with climatological $\mathrm{OH}$.

After 2007, McNorton et al. (2016a), based on methylchloroform measurements, found that global $\mathrm{OH}$ concentrations decreased after 2007 (up to $-6 \%$ between 2005 and 2010, their Fig. 1d). Consistently, Dalsøren et al. (2016) suggested that the recent methane increase is due first to high emissions in 2007-2008 followed by a stabilisation in methane loss due to meteorological variability (warm year 2010), both leading to an increase in methane atmospheric burden. Rigby et al. (2017) also infer a decrease in OH. They implement a methyl-chloroform-based box model approach to derive a 64-70\% probability that a decline in $\mathrm{OH}$ has contributed to the post-2007 methane rise. Indeed, decreasing $\mathrm{OH}$ after 2007 would limit the need for a step jump of emissions in 2007-2008 and also possibly implies a different partitioning of emission types to match the atmospheric $\delta^{13} \mathrm{C}$ evolution. Such $\mathrm{OH}$ decrease would increase the discrepancies between bottom-up inventories and top-down inversions presented in this paper. However, Turner et al. (2017), also inferring a decrease in $\mathrm{OH}$ concentrations but from 2003 to 2016, note that the under-constrained characteristics of the inverse problem prevents them from drawing definitive conclusions on the magnitude of the contribution of $\mathrm{OH}$ change to the renewed increase in atmospheric methane since 2007. Investigating the methane lifetime due to its oxidation by tropospheric OH in three different CTMs, Holmes et al. (2013) infer a consistent decrease in this lifetime from 2005 to 2009 in all models and from 2000 for some simulations, implying an increase in $\mathrm{OH}$ concentrations over this period of few per cents. They do not show results after 2009, but Dalsoren et al. (2016) do, with consistent decreasing methane-OH lifetime until 2007 and more stable $\mathrm{OH}$ concentrations afterwards. Overall and beyond the fact that most of these different studies capture the $\mathrm{OH}$ increase during the big El NiñoSouthern Oscillation of 1997-1998, year-to-year variations and trends of $\mathrm{OH}$ concentrations since 2000 still need further investigation to reconcile the small changes inferred by CTMs compared to the larger changes found in MCF-based approaches (Holmes et al., 2013). 


\section{Conclusions}

Following the decadal methane budget published by Saunois et al. (2016) for the time period 2000-2012, variations of methane sources over the same period are synthesised from an ensemble of top-down and bottom-up approaches gathered under the umbrella of the Global Carbon Project - Global Methane Budget initiative. The mean top-down model ensemble suggests that annual global methane emissions have increased between 2000 and 2012 by $15-33 \mathrm{Tg}$ $\mathrm{CH}_{4} \mathrm{yr}^{-1}$ with a main contribution from the tropics, with additional emissions from the mid-latitudes, but showing no signal from high latitudes. We suggest that global methane emissions have experienced a shift between 2006 and 2008 resulting from an increase in both natural and anthropogenic emissions. Based on the top-down ensemble mean, during 2000-2006, increasing anthropogenic emissions were compensated for by decreasing natural emissions and, during 2008-2012, both anthropogenic and natural emissions were rather stable.

To further investigate the apparent source shift, we have analysed the emission changes between 2002-2006 and 2008-2012. The top-down ensemble mean shows that annual global methane emissions increased by 20 [13-32] Tg $\mathrm{CH}_{4} \mathrm{yr}^{-1}$ between these two time periods, with the tropics contributing about $80 \%$ to this change and the remainder coming from the mid-latitudes. The regional contributions are more uncertain, especially in the tropics where tropical South America and South and East Asia are the main contributors, although contrasting contributions from South East Asia among inversions are inferred. Such regional uncertainties are due to a lack of measurements from surface stations in key tropical regions, forcing inversion systems to estimate emissions in regions without observational constraints. A consistent result among the top-down inverse models is that their inferred global emission increases are much lower than those estimated from the bottom-up approaches. This is particularly due to an overestimation of the increase in the anthropogenic emissions from China.

As methane atmospheric observations alone cannot be used to fully distinguish between methane emission processes, sectorial estimates have been reported for only five broad categories. The ensemble of top-down studies gathered here suggests a dominant contribution to the global emission increase from microbial sources $\left(+16 \mathrm{Tg} \mathrm{CH}_{4} \mathrm{yr}^{-1}\right.$ with +10 [7-12] $\mathrm{Tg} \mathrm{CH}_{4} \mathrm{yr}^{-1}$ from agriculture and waste and $+6[-4-16] \mathrm{Tg} \mathrm{CH}_{4} \mathrm{yr}^{-1}$ from wetlands) and an uncertain but smaller contribution of $+7[-2-16] \mathrm{Tg} \mathrm{CH}_{4} \mathrm{yr}^{-1}$ from fossil-fuel-related emissions from 2000-2006 to 2008-2012. In the top-down ensemble, biomass burning emissions decreased by $-3[-7-0] \mathrm{Tg} \mathrm{CH}_{4} \mathrm{yr}^{-1}$. Interestingly, the magnitudes of these mean changes for individual source sectors based on ensemble mean results from top-down approaches are consistent with isotopic observations (Schaefer et al., 2016), while the individual inversions are gener- ally not. However, the uncertainties of these mean emission changes are very large, as shown by the range inferred by inversions.

The interpretation of changes in atmospheric methane in this study is limited mostly to changes in terms of changes in methane emissions. The results from the inversions presented here mostly assume constant $\mathrm{OH}$ concentrations over the period 2000-2012 (though including seasonal variations, Table S2). As a result, changes in methane loss through $\mathrm{OH}$ oxidation in the atmosphere and soil uptake of methane are not addressed here, and their contribution needs to be further investigated to better understand the observed growth rate changes during the analysed period. Indeed, the inferred shift in emissions during 2006-2008 would likely be much smoother if $\mathrm{OH}$ concentrations decreased during these 3 years after a period of increase, as suggested in recent studies (e.g. Dalsoren et al., 2016). Estimating and optimising $\mathrm{OH}$ oxidation in top-down approaches is challenging due to the major disagreements in $\mathrm{OH}$ fields simulated by the models. Although beneficial for the recovery of the stratospheric ozone, methyl-chloroform, which is used as a proxy to derive $\mathrm{OH}$ variations, is decreasing rapidly in the atmosphere. MCF is therefore less sensitive to uncertain and larger emission as in the 1980s and 1990s (e.g. Kroll et al., 2003; Prinn et al., 2001) but within years is also less useful to derive $\mathrm{OH}$ changes as atmospheric concentrations are getting as small as the precision and accuracy of the measurements.

This also implies that we need new proxies to infer and constrain global $\mathrm{OH}$ concentrations. Chemistry climate models may be useful to provide $\mathrm{OH} 4 \mathrm{D}$ fields and to estimate its impact on lifetime, though large discrepancies exist, especially at the regional scale (Naik et al., 2013).

The global methane budget is far from being understood. Indeed, the recent acceleration of the methane atmospheric growth rate in 2014 and 2015 (Ed Dlugokencky; NOAA ESRL, www.esrl.noaa.gov/gmd/ccgg/trends_ch4/) adds more challenges to our understanding of the methane global budget. The next Global Methane Budget will aim to include data from these recent years and make use of additional surface observations from different tracers and satellite data to better constrain the time evolution of atmospheric methane burden.

Data availability. The datasets used in this paper are those collected for The Global Methane Budget 2000-2012 (Saunois et al., 2016). The decadal budget is publicly available at http://doi.org/ 10.3334/CDIAC/Global_Methane_Budget_2016_V1.1 and on the Global Carbon Project website. The full time series of the mean surface atmospheric methane mixing ratios are available in the Excel spreadsheets for the four networks. For each top-down and bottomup estimate, only the decadal budget is provided. The data from each study that serve to discuss the variations of methane emissions are available upon request to the corresponding author. 


\section{The Supplement related to this article is available online at https://doi.org/10.5194/acp-17-11135-2017- supplement.}

Competing interests. The authors declare that they have no conflict of interest.

Acknowledgements. This collaborative international effort is part of the Global Carbon Project activity to establish and track greenhouse gas budgets and their trends. Marielle Saunois and Philippe Bousquet acknowledge the Global Carbon Project for the scientific advice and the computing support of LSCE-CEA and of the national computing center TGCC.

We acknowledge the two anonymous reviewers who helped in improving the manuscript to present the most thorough review of what is know on the recent methane budget changes.

Ben Poulter has been funded by the EU FP7 GEOCARBON project. Josep G. Canadell thanks the National Environmental Science Program - Earth Systems and Climate Change Hub for their support. Donald R. Black and Isobel J. Simpson (UCI) acknowledge funding support from NASA (NNX07AK10G). Fortunat Joos, Renato Spahni, and Ronny Schroeder acknowledge support by the Swiss National Science Foundation. Changhui Peng acknowledges the support of the National Science and Engineering Research Council of Canada (NSERC) discovery grant and China's QianRen Program. Glen P. Peters acknowledges the support of the Research Council of Norway project 209701. David Bastviken acknowledges support from the Swedish Research Council VR and ERC (grant no. 725546). Patrick Crill acknowledges support from the Swedish Research Council VR. Francesco N. Tubiello acknowledges the support of FAO Regular Programme Funding under O6 and $\mathrm{SO} 2$ for the development and maintenance of the FAOSTAT emissions database. The FAOSTAT database is supported by regular programme funding from all FAO member countries. Prabir K. Patra is partly supported by the Environment Research and Technology Development Fund (A2-1502) of the Ministry of the Environment, Japan. William J. Riley and Xiyan Xu were supported by the Director, Office of Science, Office of Biological and Environmental Research of the US Department of Energy under Contract DE-AC02-05CH11231 as part of the RGCM BGC-Climate Feedbacks SFA. Peter Bergamaschi and Mihai Alexe acknowledge support by the European Commission Seventh Framework Programme (FP7/2007-2013) project MACCII under grant agreement 283576, by the European Commission Horizon 2020 Programme project MACC-III under grant agreement 633080, and by the ESA Climate Change Initiative Greenhouse Gases Phase 2 project. Hanqin Tian and Bowen Zhang acknowledge support by the NASA Carbon Monitoring Program (NNX12AP84G, NNX14AO73G). HeonSook Kim and Shamil Maksyutov acknowledge use of the GOSAT Research Computation Facility. Nicola Gedney and Andy Wiltshire acknowledge support by the Joint DECC/Defra Met Office Hadley Centre Climate Programme (GA01101). David J. Beerling acknowledges support from an ERC Advanced grant (CDREG, 322998) and NERC (NE/J00748X/1).

The CSIRO and the Australian Government Bureau of Meteorology are thanked for their ongoing long-term support of the Cape Grim station and the Cape Grim science programme. The CSIRO flask network is supported by CSIRO Australia, the Australian Bureau of Meteorology, the Australian Institute of Marine Science, the Australian Antarctic Division, the NOAA USA, and the Meteorological Service of Canada. The operation of the AGAGE instruments at Mace Head, Trinidad Head, Cape Matatula, Ragged Point, and Cape Grim is supported by the National Aeronautic and Space Administration (NASA; grants NAG5-12669, NNX07AE89G, and NNX11AF17G to MIT and grants NNX07AE87G, NNX07AF09G, NNX11AF15G, and NNX11AF16G to SIO), the Department of Energy and Climate Change (DECC, UK) contract GA01081 to the University of Bristol, the Commonwealth Scientific and Industrial Research Organisation (CSIRO Australia), and the Bureau of Meteorology (Australia).

Marielle Saunois and Philippe Bousquet acknowledge Lyla Taylor (University of Sheffield, UK), Chris Jones (Met Office, UK), and Charlie Koven (Lawrence Berkeley National Laboratory, USA) for their participation in land surface modelling of wetland emissions. Theodore J. Bohn (ASU, USA), Jens Greinhert (GEOMAR, the Netherlands), Charles Miller (JPL, USA), and Tonatiuh Guillermo Nunez Ramirez (MPI Jena, Germany) are thanked for their useful comments and suggestions on the manuscript. Marielle Saunois and Philippe Bousquet acknowledge Martin Herold (WU, the Netherlands), Mario Herrero (CSIRO, Australia), Paul Palmer (University of Edinburgh, UK), Matthew Rigby (University of Bristol, UK), Taku Umezawa (NIES, Japan), Ray Wang (GIT, USA), Jim White (INSTAAR, USA), Tatsuya Yokota (NIES, Japan), Ayyoob Sharifi and Yoshiki Yamagata (NIES/GCP, Japan), and Lingxi Zhou (CMA, China) for their interest and discussions on the Global Carbon Project methane. Marielle Saunois and Philippe Bousquet acknowledge the initial contribution to the Global Methane Budget 2016 release and/or possibly future contribution to the next Global Methane Budget of Victor Brovkin (MPI Hamburg, Germany), Charles Curry (University of Victoria, Canada), Kyle C. McDonald (City University of New-York, USA), Julia Marshall (MPI Jena, Germany), Christine Wiedinmyer (NCAR, USA), Michiel van Weele (KNMI, Netherlands), Guido R. van der Werf (Amsterdam, Netherlands) and Paul Steele (retired from CSIRO, Australia).

Edited by: Martyn Chipperfield

Reviewed by: two anonymous referees

\section{References}

Alexe, M., Bergamaschi, P., Segers, A., Detmers, R., Butz, A., Hasekamp, O., Guerlet, S., Parker, R., Boesch, H., Frankenberg, C., Scheepmaker, R. A., Dlugokencky, E., Sweeney, C., Wofsy, S. C., and Kort, E. A.: Inverse modelling of $\mathrm{CH}_{4}$ emissions for 2010-2011 using different satellite retrieval products from GOSAT and SCIAMACHY, Atmos. Chem. Phys., 15, 113-133, https://doi.org/10.5194/acp-15-113-2015, 2015.

Aydin, M., Verhulst, K. R., Saltzman, E.S., Battle, M. O., Montzka, S.A., Blake, D. R., Tang, Q., and Prather, M.J.: Recent decreases in fossil-fuel emissions of ethane and methane derived from firn air, Nature, 476, 198-201, https://doi.org/10.1038/nature10352, 2011

Basso, L. S., Gatti, L. V., Gloor, M., Miller, J. B., Domingues, L. G., Correia, C. S. C., and Borges, V. F.: Seasonality and interan- 
nual variability of $\mathrm{CH} 4$ fluxes from the eastern Amazon Basin inferred from atmospheric mole fraction profiles, J. Geophys. Res.Atmos., 121, 168-184, https://doi.org/10.1002/2015JD023874, 2016.

Bastviken, D., Tranvik, L. J., Downing, J. A., Crill, P. M., and Enrich-Prast, A.: Freshwater Methane Emissions Offset the Continental Carbon Sink, Science, 331, 6013, 50, https://doi.org/10.1126/science.1196808, 2011.

Berchet, A., Bousquet, P., Pison, I., Locatelli, R., Chevallier, F., Paris, J.-D., Dlugokencky, E. J., Laurila, T., Hatakka, J., Viisanen, Y., Worthy, D. E. J., Nisbet, E., Fisher, R., France, J., Lowry, D., Ivakhov, V., and Hermansen, O.: Atmospheric constraints on the methane emissions from the East Siberian Shelf, Atmos. Chem. Phys., 16, 4147-4157, https://doi.org/10.5194/acp16-4147-2016, 2016.

Bergamaschi, P., Houweling, S., Segers, A., Krol, M., Frankenberg, C., Scheepmaker, R. A., Dlugokencky, E., Wofsy, S. C., Kort, E. A., Sweeney, C., Schuck, T., Brenninkmeijer, C., Chen, H., Beck, V., and Gerbig, C.: Atmospheric $\mathrm{CH}_{4}$ in the first decade of the 21st century: Inverse modeling analysis using SCIAMACHY satellite retrievals and NOAA surface measurements, J. Geophys. Res.-Atmos., 118, 7350-7369, https://doi.org/10.1002/jgrd.50480, 2013.

Bridgham, S. D., H. Cadillo-Quiroz, J. K. Keller, an Zhuang, Q.: Methane emissions from wetlands: Biogeochemical, microbial, and modeling perspectives from local to global scales, Glob. Change Biol., 19, 1325-1346, 2013.

Bohn, T. J., Melton, J. R., Ito, A., Kleinen, T., Spahni, R., Stocker, B. D., Zhang, B., Zhu, X., Schroeder, R., Glagolev, M. V., Maksyutov, S., Brovkin, V., Chen, G., Denisov, S. N., Eliseev, A. V., Gallego-Sala, A., McDonald, K. C., Rawlins, M. A., Riley, W. J., Subin, Z. M., Tian, H., Zhuang, Q., and Kaplan, J. O.: WETCHIMP-WSL: Ïntercomparison of wetland methane emissions models over West Siberia, Biogeosciences, 12, 3321-3349, https://doi.org/10.5194/bg-12-3321-2015, 2015.

Bousquet, P., Ciais, P., Miller, J. B., Dlugokencky, E. J., Hauglustaine, D. A., Prigent, C., Van der Werf, G. R., Peylin, P., Brunke, E. G., Carouge, C., Langenfelds, R. L., Lathiere, J., Papa, F., Ramonet, M., Schmidt, M., Steele, L. P., Tyler, S. C., and White, J.: Contribution of anthropogenic and natural sources to atmospheric methane variability, Nature, 443, 439-443, 2006.

Bousquet, P., Ringeval, B., Pison, I., Dlugokencky, E. J., Brunke, E.G., Carouge, C., Chevallier, F., Fortems-Cheiney, A., Frankenberg, C., Hauglustaine, D. A., Krummel, P. B., Langenfelds, R. L., Ramonet, M., Schmidt, M., Steele, L. P., Szopa, S., Yver, C., Viovy, N., and Ciais, P.: Source attribution of the changes in atmospheric methane for 2006-2008, Atmos. Chem. Phys., 11, 3689-3700, https://doi.org/10.5194/acp-11-3689-2011, 2011.

Bruhwiler, L., Dlugokencky, E., Masarie, K., Ishizawa, M., Andrews, A., Miller, J., Sweeney, C., Tans, P., and Worthy, D.: CarbonTracker-CH4: an assimilation system for estimating emissions of atmospheric methane, Atmos. Chem. Phys., 14, 82698293, https://doi.org/10.5194/acp-14-8269-2014, 2014.

Bruhwiler, L. M., Basu, S., Bergamaschi, P., Bousquet, P., Dlugokencky, E., Houweling, S., Ishizawa, M., Kim, H.-S., Locatelli, R., Maksyutov, S., Montzka, S., Pandey, S., Patra, P. K., Petron, G., Saunois, M., Sweeney, C., Schwietzke, S., Tans, P., and Weatherhead, E. C.: US $\mathrm{CH}_{4}$ Emissions from Oil and Gas Production: Have Recent Large Increases
Been Detected?, J. Geophys. Res.-Atmos., 122, 4070-4083, https://doi.org/10.1002/2016JD026157, 2017.

Buchwitz, M., Reuter, M., Schneising, O., Boesch, H., Guerlet, S., Dils, B., Aben, I., Armante, R., Bergamaschi, P., Blumenstock, T., Bovensmann, H., Brunner, D., Buchmann, B., Burrows, J. P., Butz, A., Chedin, A., Chevallier, F., Crevoisier, C. D., Deutscher, N. M., Frankenberg, C., Hase, F., Hasekamp, O. P., Heymann, J., Kaminski, T., Laeng, A., Lichtenberg, G., De Maziere, M., Noel, S., Notholt, J., Orphal, J., Popp, C., Parker, R., Scholze, M., Sussmann, R., Stiller, G. P., Warneke, T., Zehner, C., Bril, A., Crisp, D., Griffith, D. W. T., Kuze, A., O’Dell, C., Oshchepkov, S., Sherlock, V., Suto, H., Wennberg, P., Wunch, D., Yokota, T., and Yoshida, Y.: The Greenhouse Gas Climate Change Initiative (GHG-CCI): Comparison and quality assessment of nearsurface-sensitive satellite-derived $\mathrm{CO}_{2}$ and $\mathrm{CH}_{4}$ global data sets, Remote Sens. Environ., 162, 344-362, 2015.

Butz, A., Guerlet, S., Hasekamp, O., Schepers, D., and Galli, A.: Toward accurate $\mathrm{CO}_{2}$ and $\mathrm{CH}_{4}$ observations from GOSAT, Geophys. Res. Lett., 38, 2-7, https://doi.org/10.1029/2011GL047888, 2011.

Cao, M., Marshall, S., and Gregson, K.: Global carbon exchange and methane emissions from natural wetlands: Application of a process-based model, J. Geophys. Res.-Atmos., 101, 1439914414, https://doi.org/10.1029/96jd00219, 1996.

Christensen, T. R., Johansson, T., Åkerman, J., Mastepanov, M., Malmer, N., Friborg, T., Crill, P., and Svensson, B. H.: Thawing sub-arctic permafrost: Effects on vegetation and methane emissions, Geophys. Res. Lett., 31, L04501, https://doi.org/10.1029/2003GL018680, 2004.

Cressot, C., Chevallier, F., Bousquet, P., Crevoisier, C., Dlugokencky, E. J., Fortems-Cheiney, A., Frankenberg, C., Parker, R., Pison, I., Scheepmaker, R. A., Montzka, S. A., Krummel, P. B., Steele, L. P., and Langenfelds, R. L.: On the consistency between global and regional methane emissions inferred from SCIAMACHY, TANSO-FTS, IASI and surface measurements, Atmos. Chem. Phys., 14, 577-592, https://doi.org/10.5194/acp14-577-2014, 2014.

Cressot, C., Pison, I., Rayner, P. J., Bousquet, P., Fortems-Cheiney, A., and Chevallier, F.: Can we detect regional methane anomalies? A comparison between three observing systems, Atmos. Chem. Phys., 16, 9089-9108, https://doi.org/10.5194/acp-169089-2016, 2016.

Curry, C. L.: Modeling the soil consumption of atmospheric methane at the global scale, Global Biogeochem. Cy., 21, GB4012, https://doi.org/10.1029/2006gb002818, 2007.

Dalsøren, S. B., Isaksen, I. S. A., Li, L., and Richter, A.: Effect of emission changes in Southeast Asia on global hydroxyl and methane lifetime, Tellus B, 61, 588-601, https://doi.org/10.1111/j.1600-0889.2009.00429.x, 2009.

Dalsøren, S. B., Myhre, C. L., Myhre, G., Gomez-Pelaez, A. J., Søvde, O. A., Isaksen, I. S. A., Weiss, R. F., and Harth, C. M.: Atmospheric methane evolution the last 40 years, Atmos. Chem. Phys., 16, 3099-3126, https://doi.org/10.5194/acp16-3099-2016, 2016.

Dangal, S. R., Tian, H., Zhang, B., Pan, S., Lu, C., and Yang, J.: Methane emission from the global livestock sector during 18902014: magnitude, trends and spatio-temporal patterns, Glob. Change Biol., GCB13709, https://doi.org/10.1111/gcb.13709, 2017. 
Dlugokencky, E. J., Steele, L. P., Lang, P. M., and Masarie, K. A.: The Growth-Rate and Distribution of Atmospheric Methane, J. Geophys. Res.-Atmos., 99, 17021-017043, 1994.

Dlugokencky, E. J., Bruhwiler, L., White, J. W. C., Emmons, L. K., Novelli, P. C., Montzka, S. A., Masarie, K. A., Lang, P. M., Crotwell, A. M., Miller, J. B., and Gatti, L. V.: Observational constraints on recent increases in the atmospheric $\mathrm{CH}$ burden, Geophys. Res. Lett., 36, L18803, 10.1029/2009GL039780, 2009.

Dlugokencky, E. J., Nisbet, E. G., Fisher, R., and Lowry, D.: Global atmospheric methane: budget, changes and dangers, Philos. T. R. Soc. A, 369, 2058-2072, 2011.

EDGARv4.1: European Commission, Joint Research Centre (JRC)/Netherlands Environmental Assessment Agency (PBL). Emission Database for Global Atmospheric Research (EDGAR), release version 4.1, http://edgar.jrc.ec.europa.eu (last access: 10 November 2014), 2010.

EDGARv4.2FT2010: European Commission, Joint Research Centre (JRC)/Netherlands Environmental Assessment Agency (PBL). Emission Database for Global Atmospheric Research (EDGAR), release EDGARv4.2FT2010, http://edgar.jrc. ec.europa.eu, (last access: 10 November 2016), 2013.

EDGARv4.2FT2012: European Commission, Joint Research Centre (JRC)/Netherlands Environmental Assessment Agency (PBL), Emission Database for Global Atmospheric Research (EDGAR), release EDGARv4.2FT2012, http://edgar.jrc. ec.europa.eu, (last access: 10 November 2016), 2014.

Etiope, G.: Natural Gas Seepage, The Earth's Hydrocarbon Degassing, Springer International Publishing, 199 pp., 2015.

Etiope, G., Milkov, A. V., and Derbyshire, E.: Did geologic emissions of methane play any role in Quaternary climate change?, Glob. Planet. Change, 61, 79-88, https://doi.org/10.1016/j.gloplacha.2007.08.008, 2008.

FAOSTAT: Food and Agriculture Organization of the United Nations, Rome, Italy, FAOSTAT Emissions-Agriculture, http:// www.fao.org/faostat/en/\#data/GT (last access: 10 January 2017), 2017a.

FAOSTAT: Food and Agriculture Organization of the United Nations, Rome, Italy. FAOSTAT Emissions-Land Use, http:// www.fao.org/faostat/en/\#data/GL (last access: 10 January 2016), 2017b.

Francey, R. J., Steele, L. P., Langenfelds, R. L., and Pak, B. C.: High precision long-term monitoring of radiatively active and related trace gases at surface sites and from aircraft in the southern hemisphere atmosphere, J. Atmos. Sci., 56, 279-285, 1999.

Giglio, L., Randerson, J. T., and van der Werf, G. R.: Analysis of daily, monthly, and annual burned area using the fourthgeneration global fire emissions database (GFED4), J. Geophys. Res.-Biogeo., 118, 317-328, https://doi.org/10.1002/jgrg.20042, 2013.

Hausmann, P., Sussmann, R., and Smale, D.: Contribution of oil and natural gas production to renewed increase in atmospheric methane (2007-2014): top-down estimate from ethane and methane column observations, Atmos. Chem. Phys., 16, 3227-3244, https://doi.org/10.5194/acp-16-3227-2016, 2016.

Hayman, G. D., O'Connor, F. M., Dalvi, M., Clark, D. B., Gedney, N., Huntingford, C., Prigent, C., Buchwitz, M., Schneising, O., Burrows, J. P., Wilson, C., Richards, N., and Chipperfield, M.: Comparison of the HadGEM2 climate-chemistry model against in situ and SCIAMACHY atmospheric methane data, Atmos.
Chem. Phys., 14, 13257-13280, https://doi.org/10.5194/acp-1413257-2014, 2014.

Helmig, D., Rossabi, S., Hueber, J., Tans, P., Montzka, S. A., Masarie, K., Thoning, K., Plass-Duelmer, C., Claude, A., Carpenter, L. J., Lewis, A. C., Punjabi, S., Reimann, S., Vollmer, M. K., Steinbrecher, R., Hannigan, J. W., Emmons, L. K., Mahieu, E., Franco, B., Smale, D., and Pozzer, A.: Reversal of global atmospheric ethane and propane trends largely due to US oil and natural gas production, Nat. Geosci., 9, 490-495, https://doi.org/10.1038/ngeo2721, 2016

Hodson, E. L., Poulter, B., Zimmermann, N. E., Prigent, C., and Kaplan, J. O.: The El Niño Southern Oscillation and wetland methane interannual variability, Geophys. Res. Lett., 38, L08810, https://doi.org/10.1029/2011g1046861, 2011.

Höglund-Isaksson, L.: Global anthropogenic methane emissions 2005-2030: Technical mitigation potentials and costs, Atmos. Chem. Phys., 12, 9079-9096, https://doi.org/10.5194/acp-129079-2012, 2012.

Höglund-Isaksson, L.: Bottom-up simulations of methane and ethane emissions from global oil and gas systems 1980 to 2012, Environ. Res. Lett., 12, 024007, https://doi.org/10.1088/17489326/aa583e, 2017.

Höglund-Isaksson, L., Thomson, A., Kupiainen, K., Rao, S., and Janssens-Maenhout, G.: Anthropogenic methane sources, emissions and future projections, Chapter 5 in AMAP Assessment 2015: Methane as an Arctic Climate Forcer, 39-59, available at: http://www.amap.no/documents/doc/ AMAP-Assessment-2015-Methane-as-an-Arctic-climate-forcer/ 1285, (last access: 20 November 2016), 2015.

Holmes, C. D., Prather, M. J., Søvde, O. A., and Myhre, G.: Future methane, hydroxyl, and their uncertainties: key climate and emission parameters for future predictions, Atmos. Chem. Phys., 13, 285-302, https://doi.org/10.5194/acp-13-285-2013, 2013.

Houweling, S., Dentener, F., and Lelieveld, J.: Simulation of indutrsial atmospheric methane to constrain the global source strength of natural wetlands, J. Geophys. Res., 105, 17243-17255, 2000.

Houweling, S., Krol, M., Bergamaschi, P., Frankenberg, C., Dlugokencky, E. J., Morino, I., Notholt, J., Sherlock, V., Wunch, D., Beck, V., Gerbig, C., Chen, H., Kort, E. A., Röckmann, T., and Aben, I.: A multi-year methane inversion using SCIAMACHY, accounting for systematic errors using TCCON measurements, Atmos. Chem. Phys., 14, 3991-4012, https://doi.org/10.5194/acp-14-3991-2014, 2014.

IEA: excerpt from Coal Information, Key coal trends, International Energy Agency, http://www.iea.org/publications/ freepublications/publication/KeyCoalTrends.pdf, last access: 15 June 2016.

Ishizawa, M., Mabuchi, K., Shirai, T., Inoue, M., Morino, I., Uchino, O., Yoshida, Y., Maksyutov, S., and Belikov, D.: Interannual variability of $\mathrm{CO}_{2}$ exchange in Northern Eurasia inferred from GOSAT $\mathrm{XCO}_{2}$, Environ. Res. Lett., 11, 105001, https://doi.org/10.1088/1748-9326/11/10/105001, 2016.

Ito, A. and Inatomi, M.: Use of a process-based model for assessing the methane budgets of global terrestrial ecosystems and evaluation of uncertainty, Biogeosciences, 9, 759-773, https://doi.org/10.5194/bg-9-759-2012, 2012.

John, J., Fiore, A. M., Naik, V., Horowitz, L. W., and Dunne, J.: Climate versus emission drivers of methane lifetime 
from 1860 to 2100, Atmos. Chem. Phys., 12, 12021-12036, https://doi.org/10.5194/acp-12-12021-2012, 2012.

Kai, F. M., Tyler, S. C., Randerson, J. T., and Blake, D. R.: Reduced methane growth rate explained by decreased Northern Hemisphere microbial sources, Nature, 476, 194-197, 2011.

Kaiser, J. W., Heil, A., Andreae, M. O., Benedetti, A., Chubarova, N., Jones, L., Morcrette, J. J., Razinger, M., Schultz, M. G., Suttie, M., and van der Werf, G. R.: Biomass burning emissions estimated with a global fire assimilation system based on observed fire radiative power, Biogeosciences, 9, 527-554, https://doi.org/10.5194/bg-9-527-2012, 2012.

Kaplan, J. O.: Wetlands at the Last Glacial Maximum: Distribution and methane emissions, Geophys. Res. Lett., 29, 1079, https://doi.org/10.1029/2001g1013366, 2002.

Kiemle, C., Kawa, S. R., Quatrevalet, M., and Browell, E. V.: Performance simulations for a spaceborne methane lidar mission, J. Geophys. Res.-Atmos., 119, 4365-4379, https://doi.org/10.1002/2013JD021253, 2014

Kim, H.-S., Maksyutov, S., Glagolev, M. V., Machida, T., Patra, P. K., Sudo, K., and Inoue, G.: Evaluation of methane emissions from West Siberian wetlands based on inverse modeling, Environ. Res. Lett., 6, 035201, https://doi.org/10.1088/17489326/6/3/035201, 2011.

Kirschke, S., Bousquet, P., Ciais, P., Saunois, M., Canadell, J. G., Dlugokencky, E. J., Bergamaschi, P., Bergmann, D., Blake, D. R., Bruhwiler, L., Cameron-Smith, P., Castaldi, S., Chevallier, F., Feng, L., Fraser, A., Heimann, M., Hodson, E. L., Houweling, S., Josse, B., Fraser, P. J., Krummel, P. B., Lamarque, J. F., Langenfelds, R. L., Le Quere, C., Naik, V., O’Doherty, S., Palmer, P. I., Pison, I., Plummer, D., Poulter, B., Prinn, R. G., Rigby, M., Ringeval, B., Santini, M., Schmidt, M., Shindell, D. T., Simpson, I. J., Spahni, R., Steele, L. P., Strode, S. A., Sudo, K., Szopa, S., van der Werf, G. R., Voulgarakis, A., van Weele, M., Weiss, R. F., Williams, J. E., and Zeng, G.: Three decades of global methane sources and sinks, Nat. Geosci., 6, 813-823, https://doi.org/10.1038/ngeo1955, 2013.

Kleinen, T., Brovkin, V., and Schuldt, R. J.: A dynamic model of wetland extent and peat accumulation: results for the Holocene, Biogeosciences, 9, 235-248, https://doi.org/10.5194/bg-9-2352012, 2012.

Klimont, Z., Höglund-Isaksson, L., Heyes, C., Rafaj, P., Schöpp, W., Cofala, J., Borken-Kleefeld, J., Purohit, P., Kupiainen, K., Winiwarter, W., Amann, M., Zhao, B., Wang, S. X., Bertok, I., and Sander, R.: Global scenarios of air pollutants and methane: 1990-2050, in preparation, 2017.

Kort, E. A., Smith, M. L., Murray, L. T., Gvakharia, A., Brandt, A. R., Peischl, J., Ryerson, T. B., Sweeney, C., and Travis, K.: Fugitive emissions from the Bakken shale illustrate role of shale production in global ethane shift, Geophys. Res. Lett., 43, 46174623, https://doi.org/10.1002/2016GL068703, 2016.

Levin, I., Veidt, C., Vaughn, B. H., Brailsford, G., Bromley, T., Heinz, R., Lowe, D., Miller, J. B., Posz, C., and White, J. W. C.: No inter-hemispheric $\delta^{13} \mathrm{CH} 4$ trend observed, Nature, 486, E3-E4, https://doi.org/10.1038/nature11175, 2012.

Lin, X., Indira, N. K., Ramonet, M., Delmotte, M., Ciais, P., Bhatt, B. C., Reddy, M. V., Angchuk, D., Balakrishnan, S., Jorphail, S., Dorjai, T., Mahey, T. T., Patnaik, S., Begum, M., Brenninkmeijer, C., Durairaj, S., Kirubagaran, R., Schmidt, M., Swathi, P. S., Vinithkumar, N. V., Yver Kwok, C., and Gaur, V. K.: Long- lived atmospheric trace gases measurements in flask samples from three stations in India, Atmos. Chem. Phys., 15, 98199849, https://doi.org/10.5194/acp-15-9819-2015, 2015.

Lin, X., Ciais, P., Bousquet, P., Ramonet, M., Yin, Y., Balkanski, Y., Cozic, A., Delmotte, M., Evangeliou, N., Indira, N. K., Locatelli, R., Peng, S., Piao, S., Saunois, M., Swathi, P. S., Wang, R., Yver-Kwok, C., Tiwari, Y. K., and Zhou, L.: Simulating $\mathrm{CH}_{4}$ and $\mathrm{CO}_{2}$ over South and East Asia using the zoomed chemistry transport model LMDzINCA, Atmos. Chem. Phys. Discuss., https://doi.org/10.5194/acp-2016-1056, in review, 2017.

Locatelli, R., Bousquet, P., Chevallier, F., Fortems-Cheney, A., Szopa, S., Saunois, M., Agusti-Panareda, A., Bergmann, D., Bian, H., Cameron-Smith, P., Chipperfield, M. P., Gloor, E., Houweling, S., Kawa, S. R., Krol, M., Patra, P. K., Prinn, R. G., Rigby, M., Saito, R., and Wilson, C.: Impact of transport model errors on the global and regional methane emissions estimated by inverse modelling, Atmos. Chem. Phys., 13, 99179937, https://doi.org/10.5194/acp-13-9917-2013, 2013.

Locatelli, R., Bousquet, P., Saunois, M., Chevallier, F., and Cressot, C.: Sensitivity of the recent methane budget to LMDz subgrid-scale physical parameterizations, Atmos. Chem. Phys., 15, 9765-9780, https://doi.org/10.5194/acp-15-9765-2015, 2015.

Marotta, H., Pinho, L., Gudasz, C., Bastviken, D., Tranvik, L. J., and Enrich-Prast, A.: Greenhouse gas production in low-latitude lake sediments responds strongly to warming, Nature Climate Change, 4, 467-470, https://doi.org/10.1038/nclimate2222, 2014

Marthews, T. R., Dadson, S. J., Lehner, B., Abele, S., and Gedney, N.: High-resolution global topographic index values for use in large-scale hydrological modelling, Hydrol. Earth Syst. Sci., 19, 91-104, https://doi.org/10.5194/hess-19-91-2015, 2015.

Matthews, E. and Fung, I.: Methane emission from natural wetlands: Global distribution, area, and environmental characteristics of sources, Global Biogeochem. Cy., 1, 61-86, https://doi.org/10.1029/GB001i001p00061, 1987.

McNorton, J., Chipperfield, M. P., Gloor, M., Wilson, C., Feng, W., Hayman, G. D., Rigby, M., Krummel, P. B., O’Doherty, S., Prinn, R. G., Weiss, R. F., Young, D., Dlugokencky, E., and Montzka, S. A.: Role of $\mathrm{OH}$ variability in the stalling of the global atmospheric $\mathrm{CH}_{4}$ growth rate from 1999 to 2006, Atmos. Chem. Phys., 16, 7943-7956 https://doi.org/10.5194/acp16-7943-2016, 2016a.

McNorton, J., Gloor, E., Wilson, C., Hayman, G. D., Gedney, N., Comyn-Platt, E., Marthews, T., Parker, R. J., Boesch, H., and Chipperfield, M. P.: Role of regional wetland emissions in atmospheric methane variability, Geophys. Res. Lett., 43, 1143311444, https://doi.org/10.1002/2016GL070649, 2016 b.

Melton, J. R., Wania, R., Hodson, E. L., Poulter, B., Ringeval, B., Spahni, R., Bohn, T., Avis, C. A., Beerling, D. J., Chen, G., Eliseev, A. V., Denisov, S. N., Hopcroft, P. O., Lettenmaier, D. P., Riley, W. J., Singarayer, J. S., Subin, Z. M., Tian, H., Zürcher, S., Brovkin, V., van Bodegom, P. M., Kleinen, T., Yu, Z. C., and Kaplan, J. O.: Present state of global wetland extent and wetland methane modelling: conclusions from a model intercomparison project (WETCHIMP), Biogeosciences, 10, 753-788, https://doi.org/10.5194/bg-10-753-2013, 2013.

Melton, J. R. and Arora, V. K.: Competition between plant functional types in the Canadian Terrestrial Ecosystem Model (CTEM) v. 2.0, Geosci. Model Dev., 9, 323-361, https://doi.org/10.5194/gmd-9-323-2016, 2016. 
Miller, J. B., Lehman, S. J., Montzka, S. A., Sweeney, C., Miller, B. R., Karion, A., Wolak, C., Dlugokencky, E. J., Southon, J., Turnbull, J., C., and Tans, P. P.: Linking emissions of fossil fuel $\mathrm{CO}_{2}$ and other anthropogenic trace gases using atmospheric ${ }^{14} \mathrm{CO}_{2}$, J. Geophys. Res., 117, D08302, https://doi.org/10.1029/2011JD017048, 2012.

Montzka, S. A., Krol, M., Dlugokencky, E., Hall, B., Jockel, P., and Lelieveld, J.: Small Interannual Variability of Global Atmospheric Hydroxyl, Science, 331, 67-69, 2011.

Naik, V., Voulgarakis, A., Fiore, A. M., Horowitz, L. W., Lamarque, J.-F., Lin, M., Prather, M. J., Young, P. J., Bergmann, D., Cameron-Smith, P. J., Cionni, I., Collins, W. J., Dalsøren, S. B., Doherty, R., Eyring, V., Faluvegi, G., Folberth, G. A., Josse, B., Lee, Y. H., MacKenzie, I. A., Nagashima, T., van Noije, T. P. C., Plummer, D. A., Righi, M., Rumbold, S. T., Skeie, R., Shindell, D. T., Stevenson, D. S., Strode, S., Sudo, K., Szopa, S., and Zeng, G.: Preindustrial to present-day changes in tropospheric hydroxyl radical and methane lifetime from the Atmospheric Chemistry and Climate Model Intercomparison Project (ACCMIP), Atmos. Chem. Phys., 13, 5277-5298, https://doi.org/10.5194/acp13-5277-2013, 2013.

Nicewonger, M. R., Verhulst, K. R., Aydin, M, and Saltzman, E. S.: Preindustrial atmospheric ethane levels inferred from polar ice cores: A constraint on the geologic sources of atmospheric ethane and methane, Geophys. Res. Lett., 43, 214-221, https://doi.org/10.1002/2015GL066854, 2016.

Nisbet, E. G., Dlugokencky, E. J., and Bousquet, P.: Methane on the rise-again, Science, 343, 493-495, https://doi.org/10.1126/science.1247828, 2014.

Nisbet, E. G., Dlugokencky, E. J., Manning, M. R., Lowry, D., Fisher, R. E., France, J. L., Michel, S. E., Miller, J. B., White, J. W. C., Vaughn, B., Bousquet, P., Pyle, J. A., Warwick, N. J., Cain, M., Brownlow, R., Zazzeri, G., Lanoisellé, M., Manning, A. C., Gloor, E., Worthy, D. E. J., Brunke, E.-G., Labuschagne, C., Wolff, E. W., and Ganesan, A. L.: Rising atmospheric methane: 2007-2014 growth and isotopic shift, Global Biogeochem. Cy., 30, 1356-1370, https://doi.org/10.1002/2016GB005406, 2016.

Olivier, J. G. J. and Janssens-Maenhout, G.: Part III: Total Greenhouse Gas Emissions, of $\mathrm{CO}_{2}$ Emissions from Fuel Combustion, International Energy Agency, Paris, ISBN-978-92-64-21709-6, 2014.

Olivier, J. G. J., Janssens-Maenhout, G., and Peters, J. A. H. W.: Trends in global $\mathrm{CO}_{2}$ emissions - 2012 Report. Joint Research Centre of the European Commission and the Netherlands Environmental Assessment Agency (PBL), the Netherlands, 2012.

Parmentier, F. J. W., Zhang, W., Mi, Y., Zhu, X., Huissteden, J., Hayes, D. J., Zhuang, Q., Christensen, T. R., and David McGuire, A.: Rising methane emissions from northern wetlands associated with sea ice decline, Geophys. Res. Lett., 42, 7214-7222, https://doi.org/10.1002/2015GL065013, 2015.

Patra, P. K., Houweling, S., Krol, M., Bousquet, P., Belikov, D., Bergmann, D., Bian, H., Cameron-Smith, P., Chipperfield, M. P., Corbin, K., Fortems-Cheiney, A., Fraser, A., Gloor, E., Hess, P., Ito, A., Kawa, S. R., Law, R. M., Loh, Z., Maksyutov, S., Meng, L., Palmer, P. I., Prinn, R. G., Rigby, M., Saito, R., and Wilson, C.: TransCom model simulations of $\mathrm{CH}_{4}$ and related species: linking transport, surface flux and chemical loss with $\mathrm{CH}_{4}$ variability in the troposphere and lower stratosphere, Atmos.
Chem. Phys., 11, 12813-812837, https://doi.org/10.5194/acp11-12813-2011, 2011.

Patra, P. K., Saeki, T., Dlugokencky, E. J., Ishijima, K., Umezawa, T., Ito, A., Aoki, S., Morimoto, S., Kort, E. A., Crotwell, A., Ravikumar, K., and Nakazawa, T.: Regional methane emission estimation based on observed atmospheric concentrations (2002-2012), J. Meteor. Soc. Japn., 94, 85-107, https://doi.org/10.2151/jmsj.2016-006, 2016.

Peng, S. S., Piao, S. L., Bousquet, P., Ciais, P., Li, B. G., Lin, X., Tao, S., Wang, Z. P., Zhang, Y., and Zhou, F.: Inventory of anthropogenic methane emissions in Mainland China from 1980 to 2010, Atmos. Chem. Phys., 16, 14545-14562, https://doi.org/10.5194/acp-16-14545-2016, 2016

Pierangelo, C., Millet, B., Esteve, F., Alpers, M., Ehret, G., Flamant, P., Berthier, S., Gibert, F., Chomette, O., Edouart, D., Deniel, C., Bousquet, P., and Chevallier, C.: MERLIN (Methane Remote Sensing Lidar Mission): an Overview, EPJ Web of Conferences, 19, 26001, https://doi.org/10.1051/epjconf/201611926001, 2016

Pison, I., Ringeval, B., Bousquet, P., Prigent, C., and Papa, F.: Stable atmospheric methane in the 2000s: key-role of emissions from natural wetlands, Atmos. Chem. Phys., 13, 11609-11623, https://doi.org/10.5194/acp-13-11609-2013, 2013.

Poulter, B., Bousquet, P., Canadell, J., Ciais, P., Peregon, A., Saunois, M., Arora, V., Beerling, D., Brovkin, V., Jones, C., Joos, F., Gedney, N., Ito, A., Kleinen, T., Koven, C., MacDonald, K., Melton, J., Peng, C., Peng, S., Schroder, R., Prigent, C., Riley, B., Saito, M., Spahni, R., Tian, H., Taylor, L., Viovy, N., Wilton, D., Wiltshire, A., Xu, X., and Zhang, Z.: Global wetland contribution to 2000-2012 atmospheric methane growth rate dynamics, Environ. Res. Lett., 12, 094013, https://doi.org/10.1088/17489326/aa8391, 2017.

Randerson, J. T., Chen, Y., van der Werf, G. R., Rogers, B. M., and Morton, D. C.: Global burned area and biomass burning emissions from small fires, J. Geophys. Res.-Biogeo., 117, G04012, https://doi.org/10.1029/2012jg002128, 2012.

Rigby, M., Prinn, R. G., Fraser, P. J., Simmonds, P. G., Langenfelds, R. L., Huang, J., Cunnold, D. M., Steele, L. P., Krummel, P. B., Weiss, R. F., O’Doherty, S., Salameh, P. K., Wang, H. J., Harth, C. M., Mühle, J., and Porter, L. W.: Renewed growth of atmospheric methane, Geophys. Res. Lett., 35, L22805, https://doi.org/10.1029/2008g1036037, 2008.

Riley, W. J., Subin, Z. M., Lawrence, D. M., Swenson, S. C., Torn, M. S., Meng, L., Mahowald, N. M., and Hess, P.: Barriers to predicting changes in global terrestrial methane fluxes: analyses using CLM4Me, a methane biogeochemistry model integrated in CESM, Biogeosciences, 8, 1925-1953, https://doi.org/10.5194/bg-8-1925-2011, 2011.

Ringeval, B., Friedlingstein, P., Koven, C., Ciais, P., de NobletDucoudre, N., Decharme, B., and Cadule, P.: Climate$\mathrm{CH}_{4}$ feedback from wetlands and its interaction with the climate- $\mathrm{CO}_{2}$ feedback, Biogeosciences, 8, 2137-2157, https://doi.org/10.5194/bg-8-2137-2011, 2011.

Rogelj, J., McCollum, D., and Smith, S.: The Emissions Gap Report 2014 - a UNEP synthesis report: Chapter 2, UN Environment Programme, Nairobi, Internet: https://wedocs.unep.org/bitstream/handle/ 20.500.11822/9345/-TheEmissionsGapReport2014: aUNEPsynthesisreport-November2014EGR_2014_Lowres. 
pdf?sequence $=3 \&$ is Allowed $=y$ (last access: 1 September 2017), ISBN: 978-92-807-3413-3, 2014.

Saad, K. M., Wunch, D., Deutscher, N. M., Griffith, D. W. T., Hase, F., De Mazière, M., Notholt, J., Pollard, D. F., Roehl, C. M., Schneider, M., Sussmann, R., Warneke, T., and Wennberg, P. O.: Seasonal variability of stratospheric methane: implications for constraining tropospheric methane budgets using total column observations, Atmos. Chem. Phys., 16, 14003-14024, https://doi.org/10.5194/acp-16-14003-2016, 2016.

Saito, M., Kim, H.-S., Ito, A., Yokota, T., and Maksyutov, S.: Enhanced Methane Emissions during Amazonian Drought by Biomass Burning, PLoS ONE 11, e0166039, https://doi.org/10.1371/journal.pone.0166039, 2016

Sanderson, M. G.: Biomass of termites and their emissions of methane and carbon dioxide: A global database, Global Biogeochem. Cy., 10, 543-557, 1996.

Saunois, M., Bousquet, P., Poulter, B., Peregon, A., Ciais, P., Canadell, J. G., Dlugokencky, E. J., Etiope, G., Bastviken, D., Houweling, S., Janssens-Maenhout, G., Tubiello, F. N., Castaldi, S., Jackson, R. B., Alexe, M., Arora, V. K., Beerling, D. J., Bergamaschi, P., Blake, D. R., Brailsford, G., Brovkin, V., Bruhwiler, L., Crevoisier, C., Crill, P., Kovey, K., Curry, C., Frankenberg, C., Gedney, N., Höglund-Isaksson, L., Ishizawa, M., Ito, A., Joos, F., Kim, H.-S., Kleinen, T., Krummel, P., Lamarque, J.-F., Langenfelds, R., Locatelli, R., Machida, T., Maksyutov, S., McDonald, K. C., Marshall, J., Melton, J. R., Morino, I., Naik, V., O'Doherty, S., Parmentier, F.-J. W., Patra, P. K., Peng, C., Peng, S., Peters, G. P., Pison, I., Prigent, C., Prinn, R., Ramonet, M., Riley, W. J., Saito, M., Santini, M., Schroeder, R., Simpson, I. J., Spahni, R., Steele, P., Takizawa, A., Thornton, B. F., Tian, H., Tohjima, Y., Viovy, N., Voulgarakis, A., van Weele, M., van der Werf, G., Weiss, R., Wiedinmyer, C., Wilton, D. J., Wiltshire, A., Worthy, D., Wunch, D. B., Xu, X., Yoshida, Y., Zhang, B., Zhang, Z., and Zhu, Q.: The Global Methane Budget 2000-2012, Earth Syst. Sci. Data, 8, 697-752, https://doi.org/10.5194/essd-8-697-2016, 2016.

Schaefer, H., Fletcher, S. E. M., Veidt, C., Lassey, K. R., Brailsford, G. W., Bromley, T. M., Dlugokencky, E. J., Michel, S. E., Miller, J. B., Levin, I., Lowe, D. C., Martin, R. J., Vaughn, B. H., and White, J. W. C.: A 21st century shift from fossil-fuel to biogenic methane emissions indicated by ${ }^{13} \mathrm{CH}_{4}$, Science, 352, 80-84, https://doi.org/10.1126/science.aad2705, 2016.

Schroeder, R., McDonald, K. C., Chapman, B .D., Jensen, K., Podest, E., Tessler, Z. D., Bohn, T. J., and Zimmermann, R.: Development and Evaluation of a Multi-Year Fractional Surface Water Data Set Derived from Active/Passive Microwave Remote Sensing Data, Remote Sens., 7, 16688-16732, https://doi.org/10.3390/rs71215843, 2015.

Schwietzke, S, Sherwood, O. A., Bruhwiler, L. M. P., Miller, J. B., Etiope, G., Dlugokencky, E. J., Michel, S. E., Arline, V.A., vaughn, B. H., White, J. W. C., and Tans, P. P.: Upward revision of global fossil fuel methane emissions based on isotope database, Nature, 538, 88-91, https://doi.org/10.1038/nature19797, 2016.

Sherwood, O. A., Schwietzke, S., Arling, V. A., and Etiope, G.: Global Inventory of Gas Geochemistry Data from Fossil Fuel, Microbial and Biomass Burning Sources, Version 2017, Earth Syst. Sci. Data Discuss., https://doi.org/10.5194/essd-2017-20, in review, 2017.
Simpson, I. J., Sulbaek Andersen, M. P., Meinardi, S., Bruhwiler, L., Blake, N. J., Helmig, D., Rowland, F. S., and Blake, D. R.: Long-term decline of global atmospheric ethane concentrations and implications for methane, Nature, 488, 490-494, https://doi.org/10.1038/nature11342, 2012.

Spahni, R., Wania, R., Neef, L., van Weele, M., Pison, I., Bousquet, P., Frankenberg, C., Foster, P. N., Joos, F., Prentice, I. C., and van Velthoven, P.: Constraining global methane emissions and uptake by ecosystems, Biogeosciences, 8, 1643-1665, https://doi.org/10.5194/bg-8-1643-2011, 2011.

Sweeney, C., Dlugokencky, E., Miller, C., Wofsy, S., Karion, A., Dinardo, S., Chang, R. Y. W., Miller, J., Bruhwiler, L., Crotwell, A., Newberger, T., McKain, K., Stone, R., Wolter, S., Lang, P. and Tans, P.: No significant increase in long-term $\mathrm{CH} 4$ emissions on North Slope of Alaska despite significant increase in air temperature, Geophys. Res. Lett., 43, 6604-6611, https://doi.org/10.1002/2016GL069292, 2016.

Tian, H., Xu, X., Liu, M., Ren, W., Zhang, C., Chen, G., and Lu, C.: Spatial and temporal patterns of $\mathrm{CH}_{4}$ and $\mathrm{N}_{2} \mathrm{O}$ fluxes in terrestrial ecosystems of North America during 1979-2008: application of a global biogeochemistry model, Biogeosciences, 7, 2673-2694, https://doi.org/10.5194/bg-7-2673-2010, 2010.

Tian, H., Chen, G., Lu, C., Xu, X., Ren, W., Zhang, B., Banger, K., Tao, B., Pan, S., Liu, M., Zhang, C., Bruhwiler, L., and Wofsy, S.: Global methane and nitrous oxide emissions from terrestrial ecosystems due to multiple environmental changes, Ecosystem Health and Sustainability, 1, 1-20, https://doi.org/10.1890/ehs14-0015.1, 2015.

Tian, H., Lu, C., Ciais, P., Michalak, A. M., Canadell, J. G., Saikawa, E., Huntzinger, D. N., Gurney, K., Sitch, S., Zhang, B., Yang, J., Bousquet, P., Bruhwiler, L., Chen, G., Dlugokencky, E., Friedlingstein, P., Melillo, J., Pan, S., Poulter, B., Prinn, R., Saunois, M., Schwalm, C. R., and Wofsy, S. C.: The terrestrial biosphere as a net source of greenhouse gases to the atmosphere, Nature, 531, 225-228, https://doi.org/10.1038/nature16946, 2016.

Thompson, R. L., Stohl, A., Zhou, L. X., Dlugokencky, E., Fukuyama, Y., Thojima, Y., Kim, S.-Y., Lee, H., Nisbet, E. G., Fisher, R. E., Lowry, D., Weiss, R. F., Prinn, R. G., O’Doherty, S., Young, D., and White, J. W. C.: Methane emis- sions in East Asia for 2000-2011 estimated using an atmospheric Bayesian inversion, J. Geophys. Res.-Atmos., 120, 4352-4369, https://doi.org/10.1002/2014JD022394, 2015.

Thonat, T., Saunois, M., Bousquet, P., Pison, I., Tan, Z., Zhuang, Q., Crill, P. M., Thornton, B. F., Bastviken, D., Dlugokencky, E. J., Zimov, N., Laurila, T., Hatakka, J., Hermansen, O., and Worthy, D. E. J.: Detectability of Arctic methane sources at six sites performing continuous atmospheric measurements, Atmos. Chem. Phys., 17, 8371-8394, https://doi.org/10.5194/acp17-8371-2017, 2017.

Thornton, B. F., Wik, M., and Crill, P. M.: Doublecounting challenges the accuracy of high-latitude methane inventories, Geophys. Res. Lett., 43, 12569-12577, https://doi.org/10.1002/2016GL071772, 2016.

Tubiello, F. N., Salvatore, M., Rossi, S., Ferrara, A., Fitton, N., and Smith, P.: The FAOSTAT database of greenhouse gas emissions from agriculture, Environ. Res. Lett., 8, 015009, https://doi.org/10.1088/1748-9326/8/1/015009, 2013. 
Tubiello, F. N., Salvatore, M., Ferrara, House, J., Federici, S., Rossi, S., Biancalani, R., Condor Golec, RD, Jacobs, H., Flammini, A., Prosperi, P., Cardenas-Galindo, P., Schmidhuber, J., SanzSnachez, M. J., Srivastava, N., and Smith, P., The Contribution of Agriculture, Forestry and other Land -Use activities to Global Warming, 1990-2012, Glob. Change Biol., 21, 26552660, https://doi.org/10.1111/gcb.12865, 2015.

USEPA: Global anthropogenic non- $\mathrm{CO}_{2}$ greenhouse gas emissions: 1990-2020, United States Environmental Protection Agency, Washington DC, 2006.

USEPA: Draft: Global Anthropogenic Non- $\mathrm{CO}_{2}$ Greenhouse Gas Emissions: 1990-2030, EPA 430-R-03-002, United States Environmental Protection Agency, Washington DC, 2011.

USEPA: Global Anthropogenic Non- $\mathrm{CO}_{2}$ Greenhouse Gas Emissions 1990-2030, EPA 430-R-12-006, US Environmental Protection Agency, Washington DC, 2012.

van der Werf, G. R., Randerson, J. T., Giglio, L., Collatz, G. J., Mu, M., Kasibhatla, P. S., Morton, D. C., DeFries, R. S., Jin, Y., and van Leeuwen, T. T.: Global fire emissions and the contribution of deforestation, savanna, forest, agricultural, and peat fires (1997-2009), Atmos. Chem. Phys., 10, 11707-11735, https://doi.org/10.5194/acp-10-11707-2010, 2010.

Voulgarakis, A., Naik, V., Lamarque, J. F., Shindell, D. T., Young, P. J., Prather, M. J., Wild, O., Field, R. D., Bergmann, D., CameronSmith, P., Cionni, I., Collins, W. J., Dals $\sqrt{ } \prod$ ren, S. B., Doherty, R. M., Eyring, V., Faluvegi, G., Folberth, G. A., Horowitz, L. W., Josse, B., MacKenzie, I. A., Nagashima, T., Plummer, D. A., Righi, M., Rumbold, S. T., Stevenson, D. S., Strode, S. A., Sudo, K., Szopa, S., and Zeng, G.: Analysis of present day and future $\mathrm{OH}$ and methane lifetime in the ACCMIP simulations, Atmos. Chem. Phys., 13, 2563-2587, https://doi.org/10.5194/acp13-2563-2013, 2013.

Wang, Z., Warneke, T., Deutscher, N., Notholt, J., Karsten, U., Saunois, M., Schneider, M., Sussmann, R., Sembhi, H., Griffith, D. W. T., Pollar, D. F., Kivi, R., Petri, C., Velazco, V. A., Ramonet, M., and Chen, H.: Contributions of the troposphere and stratosphere to $\mathrm{CH} 4$ model biases, Atmos. Chem. Phys. Discuss., https://doi.org/10.5194/acp-2016-1041, in review, 2016.

Watts, J. D., Kimball, J. S., Bartsch, A., and McDonald, K. C.: Surface water inundation in the boreal-Arctic: potential impacts on regional methane emissions, Environ. Res. Lett., 9, 075001, https://doi.org/10.1088/1748-9326/9/7/075001, 2014.

Wennberg, P. O., Mui, W., Wunch, D., Kort, E. A., Blake, D. R., Atlas, E. L., Santoni, G. W., Wofsy, S. C., Diskin, G. S., Jeong, S, and Fischer, M. L.: On the Sources of Methane to the Los Angeles Atmosphere, Environ. Sci. Technol., 46, 17, 9282-9289, https://doi.org/10.1021/es301138y, 2012

Wiedinmyer, C., Akagi, S. K., Yokelson, R. J., Emmons, L. K., AlSaadi, J. A., Orlando, J. J., and Soja, A. J.: The Fire INventory from NCAR (FINN): A high resolution global model to estimate the emissions from open burning, Geosci. Model Dev., 4, 625641, https://doi.org/10.5194/gmd-4-625-2011, 2011.
Woodward, F. I. and Lomas, M. R.: Vegetation dynamics - simulating responses to climatic change, Biol. Rev., 79, 643-670, https://doi.org/10.1017/s1464793103006419, 2004.

Wunch, D., Toon, G. C., Hedelius, J. K., Vizenor, N., Roehl, C. M., Saad, K. M., Blavier, J.-F. L., Blake, D. R., and Wennberg, P. O.: Quantifying the loss of processed natural gas within California's South Coast Air Basin using long-term measurements of ethane and methane, Atmos. Chem. Phys., 16, 14091-14105, https://doi.org/10.5194/acp-16-14091-2016, 2016.

Xu, X, Riley, W. J., Koven, C. D., Billesbach, D. P., Chang, R. Y.-W., Commane, R., Euskirchen, E. S., Hartery, S., Harazono, Y., Iwata, H., McDonald, K. C., Miller, C. E., Oechel, W. C., Poulter, B., Raz-Yaseef, N., Sweeney, C., Torn, M., Wofsy, S. C., Zhang, Z., and Zona, D.: A multi-scale comparison of modeled and observed seasonal methane emissions in northern wetlands, Biogeosciences, 13, 5043-5056, https://doi.org/10.5194/bg-135043-2016, 2016

Yvon-Durocher, G., Allen, A. P., Bastviken, D., Conrad, R., Gudasz, C. St-Pierre, A., Thanh-Duc, N., and del Giorgio, P. A.: Methane fluxes show consistent temperature dependence across microbial to ecosystem scales, Nature, 507, 488-491, https://doi.org/10.1038/nature13164, 2014.

Zazzeri, G., Lowry, D., Fisher, R. E., France, J. L., Lanoisellé, M., Kelly, B. F. J., Necki, J. M., Iverach, C. P., Ginty, E., Zimnoch, M., Jasek, A., and Nisbet, E. G.: Carbon isotopic signature of coal-derived methane emissions to the atmosphere: from coalification to alteration, Atmos. Chem. Phys., 16, 13669-13680, https://doi.org/10.5194/acp-16-13669-2016, 2016.

Zhang, B., Tian, H., Ren, W., Tao, B., Lu, C., Yang, J., Banger, K., and Pan, S.: Methane emissions from global rice fields: Magnitude, spatiotemporal patterns, and environmental controls, Global Biogeochem. Cy., 30, 1246-1263, https://doi.org/10.1002/2016GB005381, 2016.

Zhu, Q., Liu, J., Peng, C., Chen, H., Fang, X., Jiang, H., Yang, G., Zhu, D., Wang, W., and Zhou, X.: Modelling methane emissions from natural wetlands by development and application of the TRIPLEX-GHG model, Geosci. Model Dev., 7, 981-999, https://doi.org/10.5194/gmd-7-981-2014, 2014.

Zhu, Q., Peng, C., Chen, H., Fang, X., Liu, J., Jiang, H., Yang, Y., and Yang, G.: Estimating global natural wetland methane emissions using process modelling: spatio-temporal patterns and contributions to atmospheric methane fluctuations, Global Ecol. Biogeogr., 24, 959-972, 2015.

Zhuravlev, R. V., Ganshin, A. V., Maksyutov, S., Oshchepkov, S. L., and Khattatov, B. V.: Estimation of global $\mathrm{CO}_{2}$ fluxes using ground-based and satellite (GOSAT) observation data with empirical orthogonal functions, Atmos. Ocean. Opt., 26, 507-516, https://doi.org/10.1134/S1024856013060158, 2013. 